Research Article

\title{
Effects of Water Inrush from Tunnel Excavation Face on the Deformation and Mechanical Performance of Shield Tunnel Segment Joints
}

\author{
Tingsheng Zhao, Wen Liu, and Zhi Ye \\ School of Civil Engineering and Mechanics, Huazhong University of Science and Technology, No. 1037, Luoyu Road, Hongshan \\ District, Wuhan 430074, China
}

Correspondence should be addressed to Zhi Ye; yz1990@hust.edu.cn

Received 5 July 2017; Accepted 3 October 2017; Published 28 December 2017

Academic Editor: Ayman S. Mosallam

\begin{abstract}
Copyright (c) 2017 Tingsheng Zhao et al. This is an open access article distributed under the Creative Commons Attribution License, which permits unrestricted use, distribution, and reproduction in any medium, provided the original work is properly cited.

Water inrush from the excavation face often occurs in the current shield construction of metro tunnels. In this study, the discontinuity of shield tunnel lining and the interaction between the tunnel segments, the grouting layer, and the surrounding rock are considered. Based on the 3D nonlinear contact theory, a hybrid model of the shield tunnel is constructed. Considering the fluid-solid coupling effect of water and soil, the influences of different water head differences on the mechanical performance and deformation of segments and joints in the shield tunnel are studied. The water gushing from the excavation face leads to vertical convergence of the cross-sectional area of the shield tunnel, and joint opening and dislocation result in sharp decrease of the waterproof capacity of joints. Meanwhile, the stress in the vicinity of segment joints increases sharply, and local cracks occur in the segment lining. The axial force, shear force, and bending moment in the joint bolt are also significantly increased. Based on the current metro standard and the computational results in this study, an emergency control criterion is put forward by means of controlling the discharge of water: the water head difference over the excavation face is required less than $4.6 \mathrm{M}$.
\end{abstract}

\section{Introduction}

Elon Musk, the CEO of Tesla, announced lately that they will excavate underground tunnels to solve the problem of ground traffic congestion, and they started a company named Boring to develop a new type of shield construction machine for this purpose. Boring, led by Steve Davis, an engineer from SpaceX, is currently building an underground tunnel network in Los Angeles. In the tunnels, cars will be transported on an electrical skateboard, which could run at the maximum speed of 130 miles per hour, enough to deliver a car from Westwood to Los Angeles in 5 minutes [1]. Therefore, underground public transportation has great potential to alleviate urban traffic congestion. In recent years, metro construction has developed rapidly in China, and over the next five years, new metro lines will be built in 42 cities, covering a total mileage of $4,448 \mathrm{~km} \mathrm{[2].} \mathrm{In}$ urban metro construction, shield tunneling is widely used, but at present, water inrush accidents occur frequently during the construction of the shield tunnel in China. Large amount of gushing water will inevitably cause unloading and deformation of the ground, very likely altering the stress and deformation of the shield tunnel and eventually affecting the service performance of subway tunnels. Lee and Ishihara [3] reported that a section of tunnel in Kaohsiung collapsed because of uncontrolled leakage of groundwater spurted from the bottom of the operation face of shield tunneling as a result of pipeline or hydraulic fracturing.

In order to ensure the safety of metro tunnel shield construction, researchers have used various methods to study the stability of the excavation face during the shield construction of the metro tunnel. The related studies mainly include determining the limit of supporting pressure for the 
excavation face, the failure mode and mechanism of the excavation face, and the influence of the surrounding environment on the stability of the excavation face. For example, Davis et al. [4] obtained the upper and lower bound stability solutions for heading collapse under undrained conditions, in consideration of three different shapes of shallow underground opening relevant to tunneling. Krause [5] calculated the limit support pressure for tunnel face failure by assuming that the failure zone was a half sphere, half circle, or quarter circle. Leca and Dormieux [6] assumed that the failure zone in front of the tunnel face consisted of a series of conical bodies, and the lower and upper bound limits were derived for the support pressure in a dry Mohr-Coulomb material. In addition, Borja [7] presented a finite element model for strain localization analysis of elastoplastic solids subjected to discontinuous displacement fields. Vermeer et al. [8] conducted a series of three-dimensional finite element simulations for tunnel face stability. The results indicated that the failure zone in front of the tunnel face was closely related to the friction angle of sand, and the limit support pressure decreased with the friction angle of sand. Schuller and Schweiger [9] conducted a series of FEM simulations of tunnel excavation, and the results demonstrated that the development of plastic shear strains leads to a failure mechanism involving shear banding that can be captured by the model. Augarde et al. [10] investigated the stability of a plane strain heading under undrained soil conditions using finite element limit analysis methods based on the lower and upper bound theorems. Lee et al. [11] numerically analyzed the influence of the seepage force generated by the flow of groundwater in the excavation face during tunnel construction and believed that the stability of the excavation face depends on the effective supporting pressure acting on the soil skeleton and the seepage force induced by the water head difference over the excavation face. The seepage force caused by groundwater flow constitutes a major part of the total supporting pressure. With the increase of groundwater table, the proportion of seepage force in the total supporting pressure tends to increase. Mollon et al. [12] analyzed the limit support pressure of the face in a circular tunnel with a kinematical approach based on a three-dimensional multiblock failure mechanism. Perazzelli et al. [13] numerically analyzed the stability of the tunnel face under seepage flow conditions with the so-called "method of slices," and the results indicated that the tensile failure of the wedge may be more critical than the shear failure if the gradient of the hydraulic head in the ground ahead of the face is high.

Most of the existing studies focus on the stability condition of the excavation face under drained or undrained conditions and the influence of unstable excavation face on the overall stress and deformation of the shield tunnel; an equivalent model is usually used to calculate the results. However, few dealt with or considered the influence of water inrush from the excavation surface of the shield tunnel (under drained condition) on segment joints when the excavation face has not become unstable and the ground surface has no large subsidence. The lining of the shield tunnel is composed of segments with a large number of joints, and these segment joints are the weakest part in the shield tunnel. Therefore, the stress and deformation of the lining are different from those of the whole tunnel. The water inrush from the excavation face will not only lead to the overall deformation of tunnel but also induce the generation of joint opening and dislocation. The contact stress between the segment and the bolt at the joint will then increase sharply and weaken the joint, and the longterm safety of the tunnel will be at risk. Therefore, in studying the influence of water inrush from the excavation face on the segments of the shield tunnel, the variations of the stress and deformation in the vicinity of segment joints should be taken into account.

Several numerical models have been developed to simulate the segment joints of shield tunnels. The models can be classified according to the simplification of joints in the model as follows: simplified equivalent models, ring with multiple hinged joint models, and beam-spring or beamshell models. In a simplified equivalent model [14], the ratio of effective lateral stiffness is introduced to reduce the overall flexural stiffness of segment lining ring, so as to represent the reduction of the overall flexural performance of the lining caused by the joint (including the segment joint and the longitudinal joint). In a multihinged ring model [15], the flexural effect of segment joints is simulated by a hinge structure, which may be one of two types: free hinge and elastic hinge. The influence of girth joints is not considered but that of longitudinal joints is exaggerated. In beam-spring or beam-shell models [16-18], a three-dimensional shell or solid element is used to simulate the segment, and the mechanical effects of segment and ring joints are simulated using rotating spring and shear spring. Thus, the planar problem is extended to a three-dimensional problem, and the longitudinal mechanical model and lateral mechanical model of the shield tunnel are unified; the requirement of fine analysis of the segment lining structure is also satisfied. However, it is extremely difficult to simulate the interaction between segment joints, especially to illustrate the cracking and dislocation of joints in case of water inrush from the excavation face.

This study takes as an example the water inrush from the excavation surface occurred during the shield construction in a section of railway from the Xiaodongmen station of Wuhan subway line 7 to the Wuchang station (Figure 1), to investigate the stress and deformation of metro tunnel segment joints when large amount of water gushes from the excavation face. This section from the Xiaodongmen to the Wuchang station (XWS) is set up in the north-south direction, with the left tunnel $1115.208 \mathrm{~m}$ long and the right tunnel $1107.169 \mathrm{~m}$ long, and mainly laid along the Zhongshan Road. The left tunnel is constructed with a Liaoning 33 shield machine, and the right tunnel is constructed with a Komatsu shield machine. An EPB (earth-pressure balance) shield tunneling machine is adopted for the excavation in the studied railway section, whose minimum radius of curvature in the horizontal plane is $400 \mathrm{~mm}$, and the spacing between the left and right tunnels is $12.6-50.5 \mathrm{~m}$; the minimum 


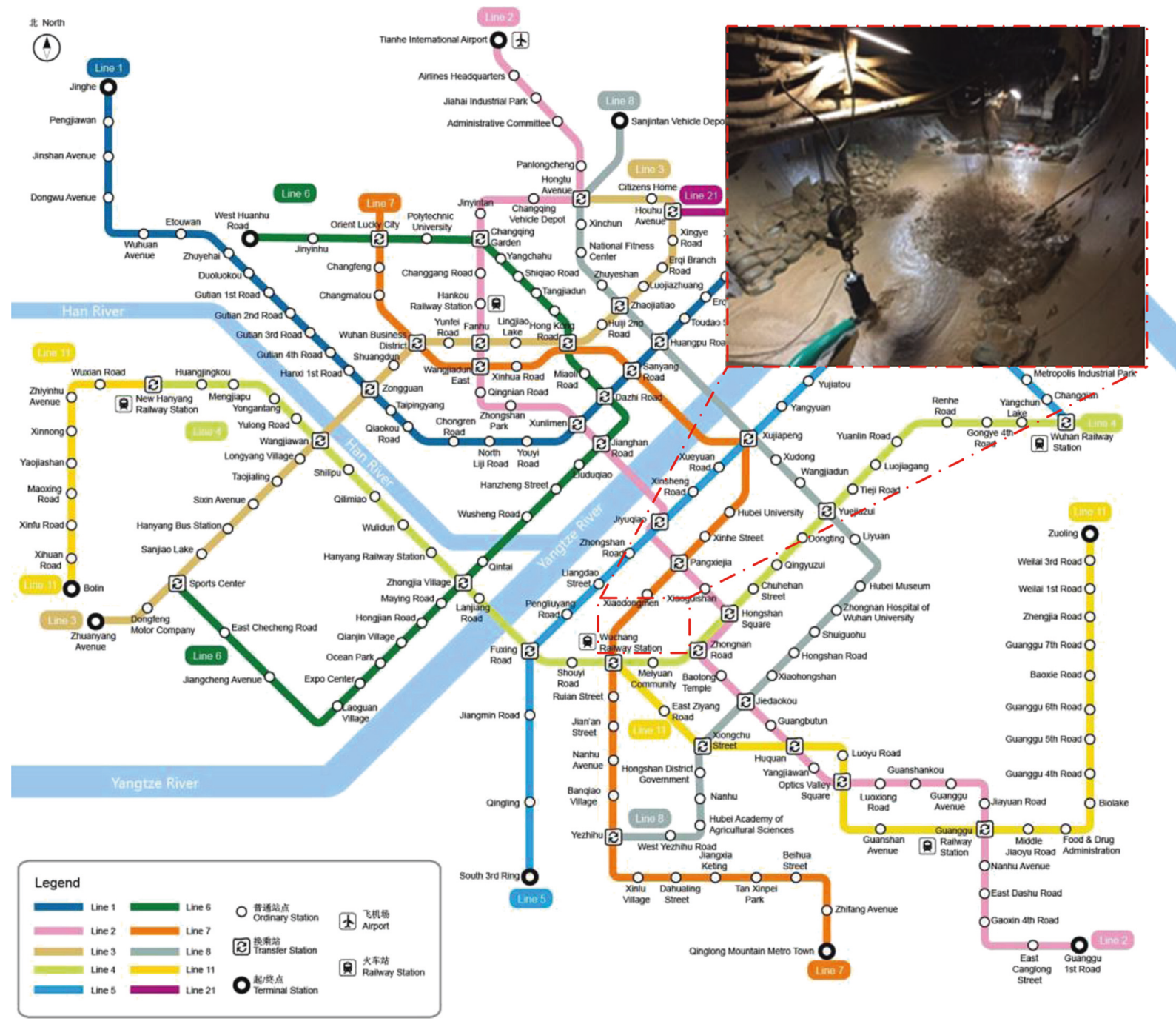

FIgURE 1: Location of the XWS in the Wuhan metro system.

radius of curvature in the longitudinal plane is $3000 \mathrm{~m}$, with "V"-shaped slopes, and the thickness of the soil cover is $10.5-45.4 \mathrm{~m}$. The tunnel structure is made of prefabricated reinforced concrete segments. The soil profile in the water gushing section of the shield tunnel is shown in Figure 2.

The rest of the paper is organized as follows: Section 2 introduces a $3 \mathrm{D}$ discontinuous contact model proposed in this study, the multiscale modeling approach, and computational parameters. Section 3 introduces and discusses the influences of water inrush from the excavation face on the segment joints of the metro tunnel. Section 4 puts forward an emergency control criterion for shield construction under the condition of water inrush from the excavation face. Finally, Section 5 summarizes the conclusions of this study.

\section{Computational and Modeling Methods}

2.1. 3D Discontinuous Contact Model. The shield tunnel is formed by assembling segments interacting with each other at the joints. In a numerical model, the interaction between nodes is treated as a complex contact action, and the differences between a 3D discontinuous contact model and other computational models lie in the setup and description of these contact relationships.

The entire calculation model is shown in Figure 3. With the stratigraphic structure method, the soil from top to bottom is divided into 5 layers, which are miscellaneous filled soil, silty clay, strongly weathered mudstone, medium weathered mudstone, and hard mudstone, and the groundwater level is -1.20 to $2.50 \mathrm{~m}$. The width, depth, and length are 100,60 , and $100 \mathrm{~m}$, respectively. In this model, individual segments are simulated by solid elements, and segment caulking and ethylene propylene diene monomer (EPDM) elastic rubber-sealing gaskets are also considered in the model. The EPDM elastomeric rubber gasket is simulated with hyperelastic solid elements, and segment bolts are simulated using beam elements with $\Phi 30 \mathrm{~mm}$ circular cross-sectional area and the actual length of individual bolts. The grouting layer and surrounding rock mass are all simulated using solid elements. 


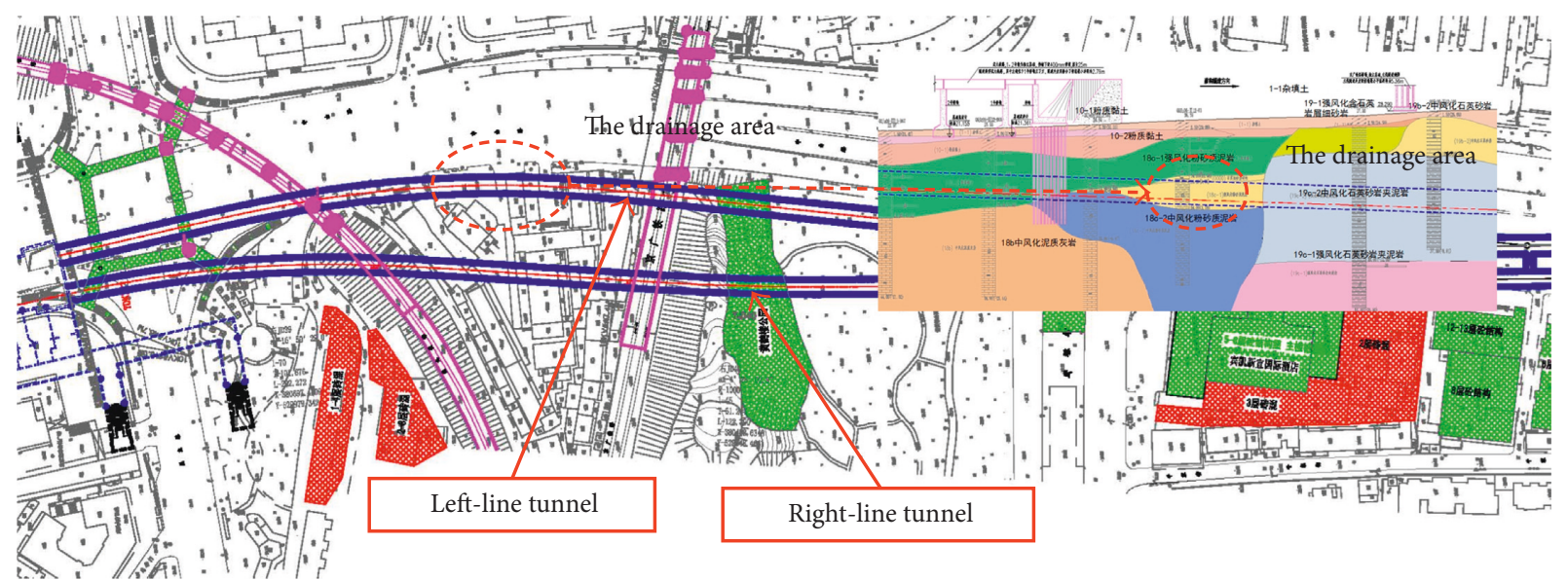

FIGURE 2: The water gushing section of XWS.

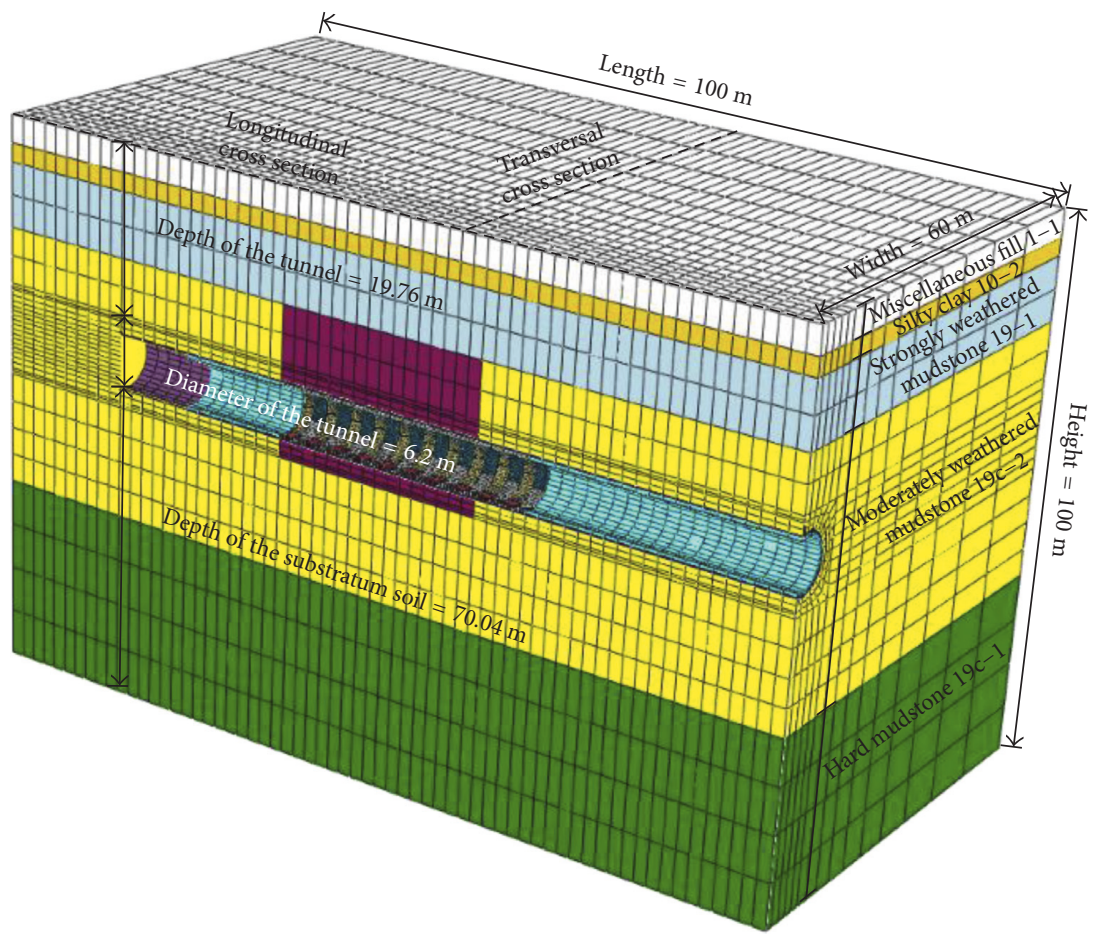

FIGURE 3: Integrity of the calculation model.

According to the data of field geological survey, the basic mechanical parameters of the soil in the water gushing area (Figure 1) during the construction of the shield tunnel are listed in Table 1. The perched water mainly occurs in the artificially filled soil layer, receiving the atmospheric precipitation and the vertical infiltration of the living water of the surrounding residents. During the exploration, the measured initial water level of the perched water is $1.20-2.50 \mathrm{~m}$ under the ground, and the static water level is 0.6 to $4.2 \mathrm{~m}$ under the ground. The pore confined water occurs in the ancient Yangtze River layer (11-1) containing clay and fine sand, in the (11-2) layer containing clay and fine-medium sand, and in the (12) layer containing fine sand mixed with gravels and receives the osmotic recharge from the confined water in the surrounding area. The karst fissure water mainly occurs in the karst fissures in limestone and argillaceous limestone, and it is generally distributed in karst areas and has weak local pressure-bearing capacity. Below the miscellaneous filled soil is saturated soil, indicating sufficient water supply and constant water head, and it is easy to cause a large number of water gushing sections in the shield construction.

Each ring-shaped segment of subway tunnel is divided into a block $\mathrm{K}$ with back cover $\left(21.5^{\circ}\right)$, two adjacent blocks $\mathrm{B}\left(68^{\circ}\right)$, and three standard blocks A $\left(67.5^{\circ}\right)$. The thickness of the segment is $350 \mathrm{~mm}$, and the width of each ring is $1.5 \mathrm{~m}$. The 
TABLE 1: Basic parameters of soil mass.

\begin{tabular}{lcccccccc}
\hline Name of soil layers & $\begin{array}{c}\text { Compressive } \\
\text { modulus }(\mathrm{kPa})\end{array}$ & $\begin{array}{c}\text { Elastic } \\
\text { modulus } \\
(\mathrm{kPa})\end{array}$ & $\begin{array}{c}\text { Poisson } \\
\text { ratio }\end{array}$ & $\begin{array}{c}\text { Cohesion } \\
(\mathrm{kPa})\end{array}$ & $\begin{array}{c}\text { Internal } \\
\text { friction angle } \\
\left({ }^{\circ}\right)\end{array}$ & $\begin{array}{c}\text { Void } \\
\text { ratio }\end{array}$ & $\begin{array}{c}\text { Saturation } \\
\text { density }\left(\mathrm{t} / \mathrm{m}^{3}\right)\end{array}$ & $\begin{array}{c}\text { Permeability } \\
\text { coefficient }(\mathrm{m} / \mathrm{s})\end{array}$ \\
\hline $\begin{array}{l}\text { Miscellaneous fill 1-1 } \\
\text { Silty clay 10-2 }\end{array}$ & 1500 & 879 & 0.36 & 8 & 18 & 0.63 & 1.85 & $1.5 * 10^{-9}$ \\
$\begin{array}{l}\text { Strongly weathered } \\
\text { mudstone 19-1 }\end{array}$ & 24,300 & 19,215 & 0.28 & 65 & 29 & 0.67 & 1.97 & $1.5 * 10^{-9}$ \\
$\begin{array}{l}\text { Moderately weathered } \\
\text { mudstone 19c-2 }\end{array}$ & 46,000 & 34,171 & 0.3 & 50 & 19 & 0.60 & 2.25 & $1 * 10^{-9}$ \\
Hard mudstone 19c-1 & 500,000 & 371,429 & 0.3 & 50 & 19 & 0.69 & 2.25 & $1 * 10^{-9}$ \\
\hline
\end{tabular}

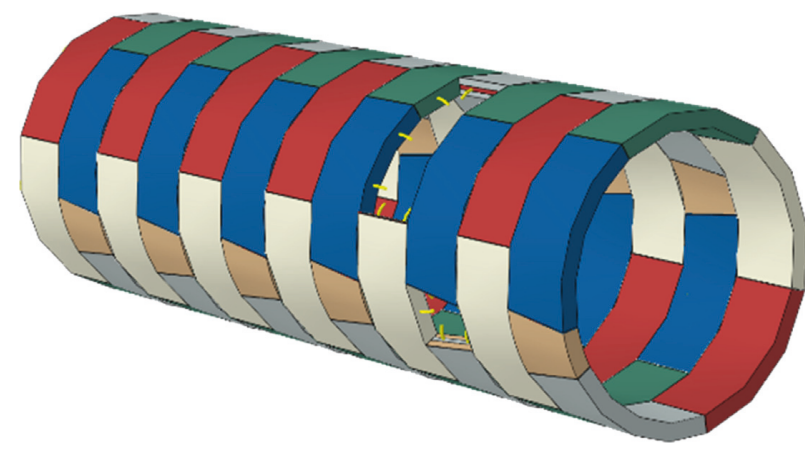

(a)

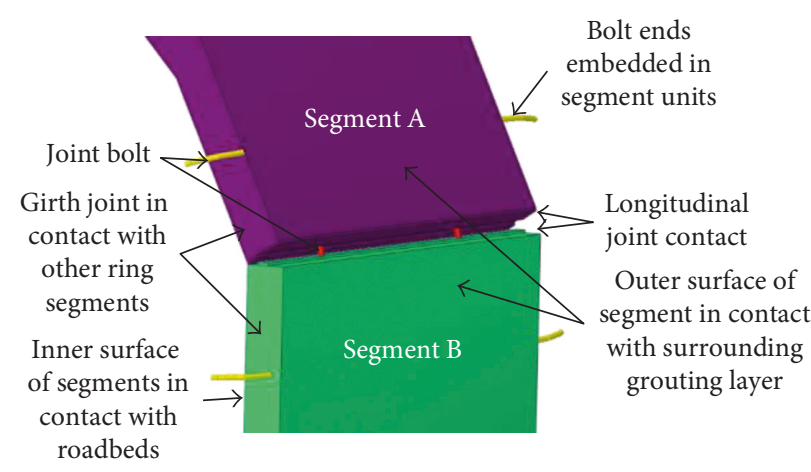

(b)

FIgURE 4: The contact relationship among the grouting layer, segment, and the surrounding rocks. (a) Model of the segmental lining. (b) 3D contact relationship.

outer diameter and inner diameter are 6.2 and $5.5 \mathrm{~m}$, respectively. The segments are assembled by staggered joints; the joint of each lining ring includes a circumferential joint with 16 bolts (M30) and a longitudinal joint with 12 bolts (M30).

Figure 4 shows the contact relationship among the grouting layer, segment, and the surrounding rocks in the calculation model. The mechanical and deformation characteristics of segment joints and the interaction between the lining with backfilling and the ground are simulated with the nonlinear contact theory. We used the master-slave algorithm for contact surface for contact searching and the finite sliding in the contact area for master-slave contact tracking, which is suitable for two known interface contact searches. A large number of master contact surface and corresponding slave surface need to be defined in building a numerical model, to reduce the processing time for a large number of contacts in the model.

The two ends of the connecting bolt are embedded into the corresponding segment elements to simulate the mechanical properties related to the tension, compression, and shear deformation of the joint, and the states of deformation of joints under different stress conditions can also be revealed. The contact property of the segment joint is "hard contact" in the normal direction, that is, the magnitude of contact stress between the contact surfaces is not limited [19]. When the contact stress is zero or negative, the two contact surfaces are separated, and the contact constraints on the corresponding nodes are reduced; meanwhile, the
Coulomb frictional force is applied in the tangent direction, according to the following formula:

$$
\tau_{\text {crit }}=\mu \times p
$$

where $\tau_{\text {crit }}$ is the critical shear stress, $\mu$ is the frictional coefficient of segment joints (i.e., 0.62), and $p$ is the contact pressure in the normal direction. No relative sliding occurs between the friction surfaces until the shear force reaches the critical shear stress.

For the contact properties between the segment and grouting layer, the rigidity model with penalisation is used in the normal direction [19]:

$$
\left\{\begin{array}{l}
p=0(\Delta l<0) \\
p>0(\Delta l=0) \\
p=f(\operatorname{kin}, \Delta l)(\Delta l>0)
\end{array}\right\},
$$

where $p$ is the normal contact force, $\Delta l$ is the embedded length, "kin" is the embedded rigidity with penalisation of the contact surface, and $f$ is the penalisation function.

The Coulomb frictional force is applied in the tangent direction, and the outer side of the grouting layer is tied with the soil mass.

2.2. Determination of Key Components with Multiscale Modeling Techniques. The purpose of this work is to analyze 


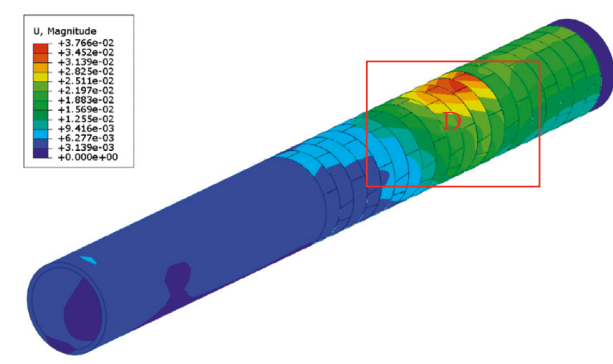

(a)

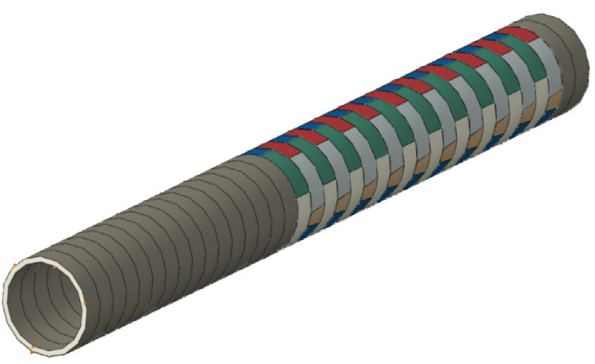

(b)

Figure 5: Multiscale hybrid model. (a) Critical section of the tunnel under water inrush. (b) Hybrid model of critical Section D.

TABLE 2: Material properties.

\begin{tabular}{lccccc}
\hline Model component & Unit weight $\left(\mathrm{kN} / \mathrm{m}^{3}\right)$ & Elastic modulus $(\mathrm{MPa})$ & Poisson ratio & External diameter $(\mathrm{m})$ & Internal diameter $(\mathrm{m})$ \\
\hline Shield machine block & 78.5 & 210,000 & 0.125 & 3.2 & 3.1 \\
Over excavation soil & 20 & 0.8 & 0.2 & 3.24 & 3.24 \\
Grouting layer (soft) & 20 & 7 & 0.2 & 3.24 & 3.1 \\
Grouting layer (hard) & 25 & 50 & 0.3 & 0.03 & 3.1 \\
Bolt & 78.5 & 210,000 & 0.125 & 3.1 & - \\
Segment & 30 & 30,000 & $\mathrm{C} 1=0.7 \mathrm{MPa}$ C $2=0.35 \mathrm{MPa} ; q=1.3 \mathrm{~g} / \mathrm{cm}^{2}$ \\
\hline EPDM & \multicolumn{5}{c}{} \\
\hline
\end{tabular}

the influence of water inrush from the excavation face on the internal force of the segment joints behind. Since the grid size and model scale are inversely proportional to the computational cost, large and full-size models are avoided in order to reduce the computing time. The multiscale modeling techniques $[20,21]$ have been developed to provide an alternative to overcome this difficulty. The macroscale for numerical calculation may cover a wide range, and the mesoscopic state of dangerous local structures can be observed through multiscale analysis. Therefore, a hybrid model using the multiscale modeling techniques is established for numerical analysis. The simplified analysis method is applied to the segment model outside the drainage area, and fine-scale numerical simulation is carried out only for the drainage area. The bolt-segment connections and mortise and tenon structures are also considered, and the other parts located certain distance away from these parts are treated by an equivalent simplified model with a relatively coarse mesh. This method enables the researchers to obtain the response of the tunnel and simultaneously obtain the distributions of deformation and stress in segment joints.

The equivalent model and the parts for fine analysis in the hybrid model are connected by setting the form of contact for the circumferential joint of segments, that is, the connection between the equivalent section and the part for fine analysis is considered as the circumferential joint between segments. The constitutive model of the Coulomb frictional force is used in the tangent direction, and "hard contact" is used in the normal direction. Similarly, each segment is assembled by high-strength bolts in the circumferential direction. On the premise of accurate calculation, transition between two grids with different mesh sizes is avoided. As shown in Figure 5, in the drainage area, fine mesh is used for the segment bolt structure, where the internal forces of both the segment and the bolt can be obtained. The first task is to identify the dangerous parts of the model. An equivalent model is used to analyze and determine the hazard zones. Under the influence of water inrush from the excavation face, the deformation nephogram of the tunnel is shown in Figure 5(a). Large vertical displacement of the tunnel (Section D) is observed after excavation, and the location of this critical section is also shown in Figure 5.

2.3. Constitutive Model and Material Parameters. According to the field construction data, a numerical model is established, which consists of five major parts: soil, shield machine, grouting layer, segment, and bolt. The shield body, grouting layer, and segment are assumed to be constituted by linear elastic materials. The hardening of flowing slurry is simulated using equivalent layer, and segment joints and bolts are also considered; the diameter of each bending bolt is $30 \mathrm{~mm}$. The specific dimensions and basic mechanical parameters of the above components are shown in Table 2 .

The shield body, grouting layer, and segment are assumed to be constituted by elastic materials, and the temporal effect in the hardening of flowing slurry is simulated with the equivalent layer. The grouting layer is divided into soft and hard grouting layers, and the thickness of the grouting layer is determined according to the actual conditions. Considering the construction parameters on site, the average grouting volume per ring is 


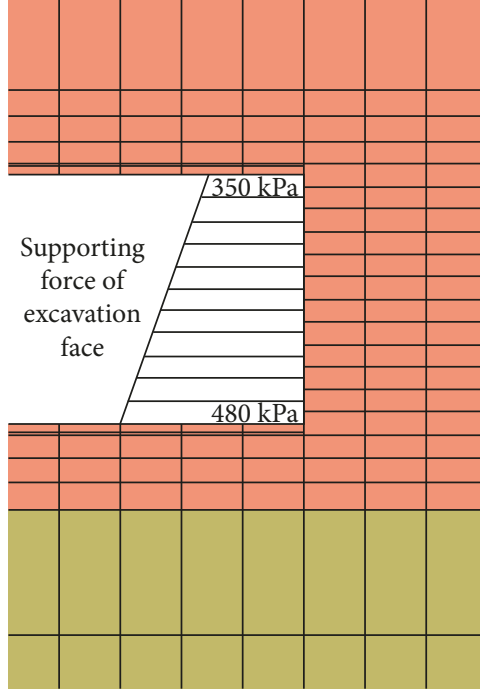

(a)

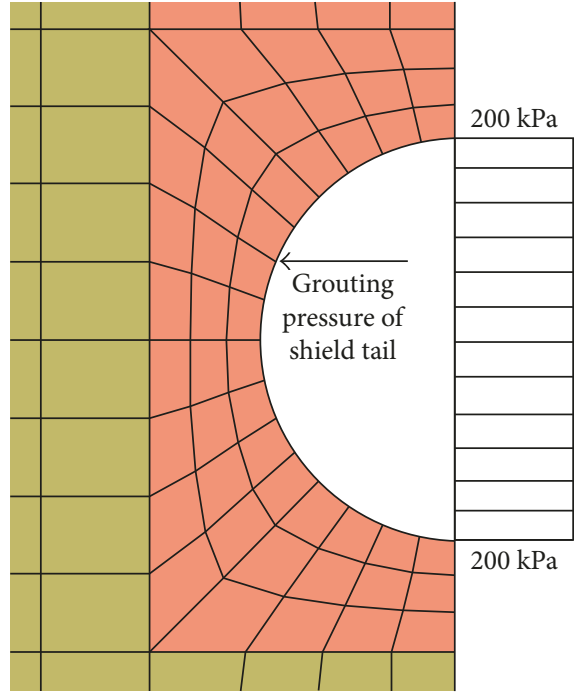

(b)

FIGURE 6: The supporting force by shield machine and grouting pressure at the shield tail. (a) The supporting force at the excavation face. (b) The grouting pressure at the shield tail.

set to be $7 \mathrm{~m}^{3}$; considering the compressibility of the slurry at the end of shield and the volume loss caused by water loss, the grouting volume is larger than that of the clearance of soil over excavation, and the grouting volume is generally $150 \%-200 \%$ of the construction clearance. According to the field conditions, the thickness of the grouting layer in the construction model is assumed to be $0.14 \mathrm{~m}$; therefore, according to (3) and the clearance volume of each ring of soil, the grouting ratio can be calculated to be $167 \%$. At the same time, the grouting pressure is applied to the outer ring of the segment and the inner wall of the soil to simulate the grouting pressure at the shield tail:

$$
V=\pi * L * \frac{\left(D^{2}-d^{2}\right)}{4} .
$$

In addition, the model introduces a $0.04 \mathrm{~m}$ thick overexcavation layer on the outer wall of the shield machine, so as to simplify the influence of the cone degree of shield machine and release the stress in the surrounding rock to some extent, making the numerical simulation closer to the actual construction process. The EPDM elastomeric gasket is modeled by the Mooney-Rivlin rubber model with two parameters: $\mathrm{C} 1$ and $\mathrm{C} 2$ are 0.7 and $0.35 \mathrm{MPa}$, respectively, and the density of gasket is $1.3 \mathrm{~g} / \mathrm{cm}^{3}$.

\subsection{Boundary Conditions Defined in the Numerical Model} and Simulation Steps. The seepage boundary is simulated by the fluid-structure interaction of water and soil analyzed with "the transient analysis of soil" in ABAQUS. The miscellaneous backfill is dry soil, and the soil below is saturated soil. Because the speed of field shield construction is fast and the segment has good water stopping effect, the excavation process does not involve water loss. Therefore, the pore pressure at the boundary of miscellaneous backfill is set to be zero, and except for the excavation surface, the other parts have undrained boundaries.

The mechanical boundaries are set as follows: the bottom of the model is a fixed boundary, only the normal displacements of the four lateral sides are restrained, and the top is a free surface.

In the process of excavation, the supporting force for the excavation face provided by the shield machine and the synchronous grouting pressure at the shield tail (as shown in Figure 6) are set as follows: the supporting force of the excavation face is $350 \mathrm{kPa}$; it increases linearly with the depth, and the gradient of increment is $20 \mathrm{kPa} / \mathrm{m}$. The force is slightly larger than the pressure imposed by the lateral static soil, in order to prevent the ground subsidence induced by the collapse of soil above and in front of the excavation face. The grouting pressure is applied to the excavation soil and the outer wall of the segment to simulate the grouting at the shield tail. The upper and lower grouting pressure is kept to be the same, and the value is $200 \mathrm{kPa}$.

A total of 57 analysis steps are set in the model, and each analysis step is 1-hour long. The tunneling proceeds step by step, and the width of each ring is $1.5 \mathrm{~m}$. The specific excavation steps are as follows.

Figure $7(a)$ is the first step in the construction of a shield tunnel. All the shield machine body enters the soil; the shield body is $9 \mathrm{~m}$ long, so the soil in $9 \mathrm{~m}$ is inactivated simultaneously. The supporting force for the excavation face is then added, and the outer ring (outside the overexcavation mass) of the shield machine is "tied" to the soil mass.

Figure 7(b) shows the second step: activate the front shield ring and kill the rear shield ring; at the same time, add the lining segment and the equivalent grouting layer and apply the grouting pressure to the inner wall of the soil and the outer ring of the lining; at the same time, 


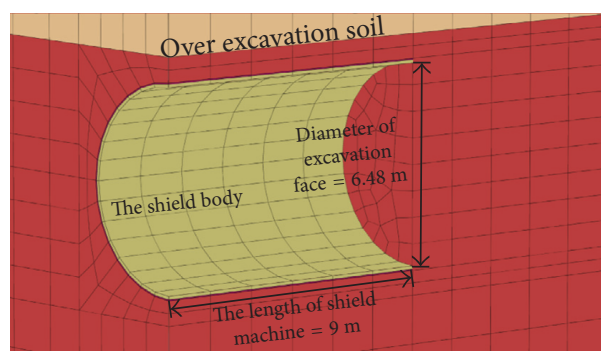

(a)

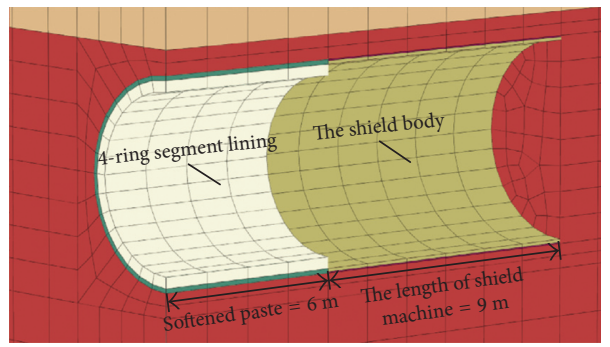

(c)

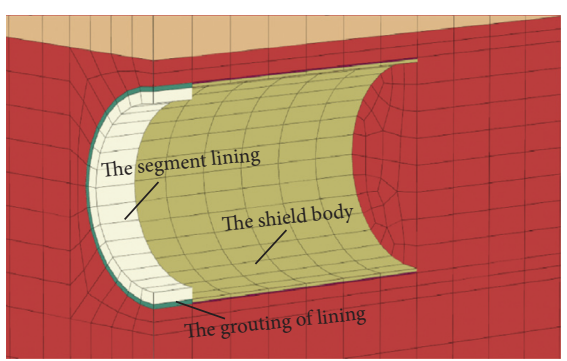

(b)

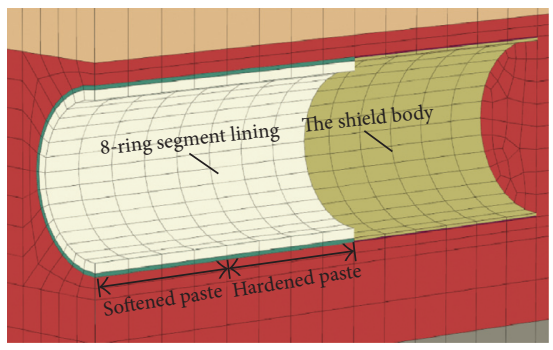

(d)

Figure 7: The simulation of the excavation of the shield tunnel. (a) The first step. (b) The second step. (c) The fifth step. (d) The sixth step.

apply the supporting force for the excavation face to ensure the stability of the excavation face. In order to simplify the calculation, the Tie constraint is applied between the exterior of the slurry and the soil and between the inner part of the slurry and the outer ring of the segment.

Figure 7(c) shows that after the fifth step, four rings have been supported by the segment grouting layer, and the lasting length of grouting pressure is 4 rings and $6 \mathrm{~m}$. At this point, the slurry strength is $7 \mathrm{MPa}$, and the slurry behaves as a flowing soft paste.

After the sixth step, the slurry at the end of the tunnel begins to harden, and the material parameters of slurry are changed using the "field" variable in ABAQUS to increase the elastic modulus until $50 \mathrm{MPa}$; in the meanwhile, the grouting pressure behind the slurry is eliminated. Figure 7 (d) shows the states of the shield machine body, lining segment, and soft-hard grouting layer after the ninth step; at this time, the segment has 8 rings, and behind the segment are 4 rings of soft paste and 4 rings of hard paste. This method is applied in sequence until the completion of 28 steps.

The water inrush from the excavation face in shield construction is a dynamic process, which gradually evolves from well-controlled drainage to small amount of drainage and then to large amount of drainage at some local segments of the excavation face. In this paper, the evolution of water inrush from the excavation face is determined by setting the water head difference over the excavation face, and fine-mesh simulation of segments and bolts is carried out to monitor the influence of water head difference on the internal force of segments and bolts. Figure 8 shows the numerical model of water gushing from the local excavation face, which in combination with the condition of construction on site and the engineering geological parameters of the corresponding sections shown in Figure 3 and Table 1 suggests that when the shield tunneling initially proceeds in mudstone with good soil conditions, no water inrush occurs from the excavation face, and when passing through water-rich sand layer such as hidden river and the karst area, earth-pressure-based shield construction is easy to cause serious water inrush from the excavation face and further cause accidents such as dislocation and cracking of the rear segments.

\section{Analysis of the Effects of Water Inrush from Shield Excavation Face}

3.1. Overall Deformation of Tunnel. Figure 9 shows the distribution of deformation of tunnel lining under the condition of water inrush from the excavation face in shield tunneling. It can be seen from Figure 9 that the water inrush results in relatively large vertical displacement of segments. The maximum vertical deviation of the tunnel axis is $32 \mathrm{~mm}$. The maximum vertical deviation angle appears on the tunnel axis in the dangerous Section D, and the hazard area of segments appears 2-3 rings behind the shield tail. The vertical deviation of adjacent segment vaults reaches $15 \mathrm{~mm}$, that is, the maximum amount of dislocation is $15 \mathrm{~mm}$.

\subsection{Segment Dislocation and Opening}

3.2.1. Deformation of Joints after Water Inrush from the Excavation Face. Water inrush from the excavation face will lead to the overall deformation of the existing lining 


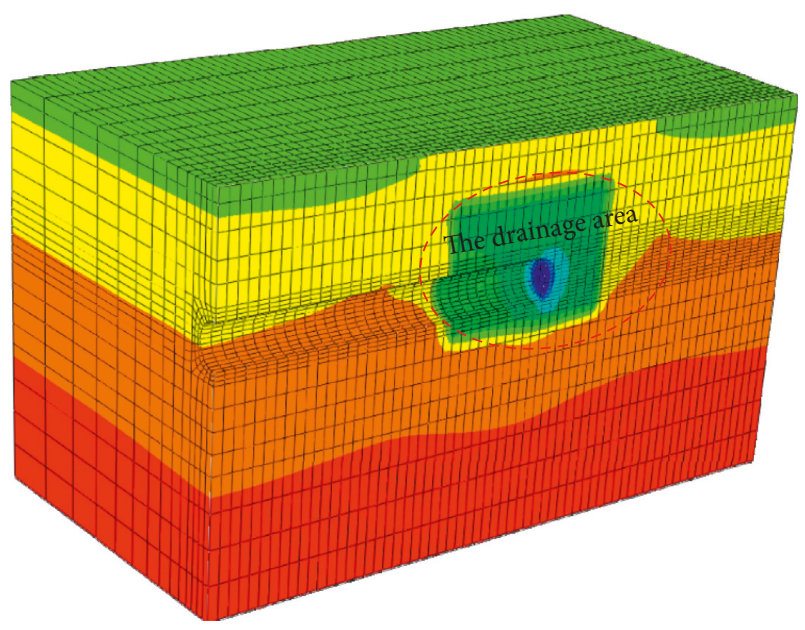

Figure 8: Local area of water inrush from the local excavation face.

and change the deformation of joints. Figures 10 and 11 show the deformation of segment joints in the critical Section D after water inrush has occurred from the excavation face.

The following conditions are observed from the diagram:

(1) After the occurrence of water inrush from the excavation face, joint dislocation and opening increase significantly in the critical Section D. This kind of joint deformation will weaken the intrinsic safety of the structure and the waterproof performance of the shield tunnel.

(2) After the occurrence of water inrush from the excavation face, dislocation usually occurs at the circumferential joints in the water gushing section, and no obvious dislocation is found at longitudinal joints. Opening occurs at longitudinal joints. The tunnel top has larger subsidence, and the volume of water gushing from the excavation face determines the size of segment dislocation and opening. Figure 10 shows the diagram of segment deformation when the excavation face is not drained and the pore water pressure of the excavation face is set to be 0 , that is, the excavation face is fully drained. As can be seen from the diagram, when the excavation face is not drained, small extrusion of 1-2 $\mathrm{mm}$ appears at the top and bottom of the segment. However, when the excavation face is fully drained, as shown in Figure 10(b), very large compressive deformation with the maximum displacement of $32.12 \mathrm{~mm}$ is found at the top of the segment. Because shield tunneling works in hard mudstone, the rebound of the lower part of the tunnel is smaller, and the main deformation of segment comes from the subsidence of tunnel vault, resulting in serious change of segment internal force. In engineering practice, segment crushing failure may be caused by water inrush.

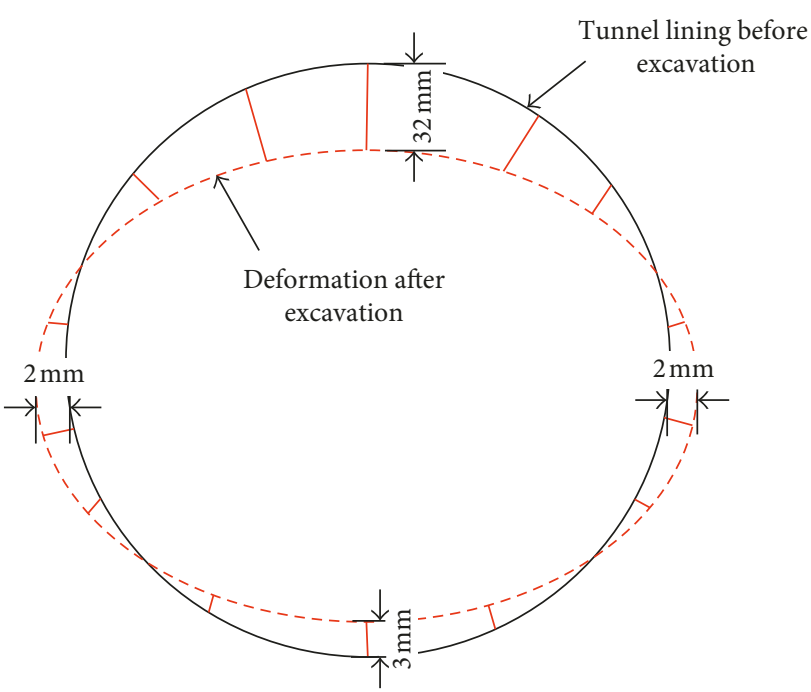

FIgURE 9: Deformation distribution of tunnel lining after water inrush.

(3) The deformation of each ring of segment is shown in Figure 11. The upper part of the segment is subjected to greater extruding failure, which will cause large dislocation of circumferential segment joints and opening of longitudinal joints. Large dislocation and opening will further result in water inrush hazard of segment joints.

3.2.2. Variation of Joint Deformation with Different Amounts of Water Gushing. With the continuous change of the amount of water gushing from the excavation face, the deformation of segment joints change continuously. Seven values of pore water pressure of the excavation face ("por") are set (0, 20, 40, 70, 100, 130 , and 160) to monitor the change of segment displacement and internal force. The pore water pressure values $0,20,40,70$, 100,130 , and 160 correspond to the reduction of water head $(\Delta h)$ of $18,16,14,11,8,5$, and $2 \mathrm{~m}$, respectively, as shown in Table 3 . The length of drainage is 6 rings, or $9 \mathrm{~m}$, and the drainage time of each ring is $5 \mathrm{~h}$, with reference to the undrained condition.

Figure 12 shows the maximum deformation of segment (caused by circumferential joint dislocation and longitudinal joint opening) in the critical Section $\mathrm{D}$, which changes with the progress of water inrush from the excavation face. The water head difference over the excavation face is varied from $0 \mathrm{~m}$ to $18 \mathrm{~m}$.

The calculation results display the following variations:

(1) When the water head difference over the excavation face is $0-5 \mathrm{~m}$, the deformation of the segment joint is smaller and the extents of joint dislocation and opening are smaller, but when the water head difference over the excavation face is $6-15 \mathrm{~m}$, the deformation of joint increases remarkably.

(2) When the water head difference over the excavation face reaches the limit value of $18 \mathrm{~m}$, longitudinal joint opening at tunnel vault reaches the maximum value of $4 \mathrm{~mm}$. Without the occurrence of water inrush, the 


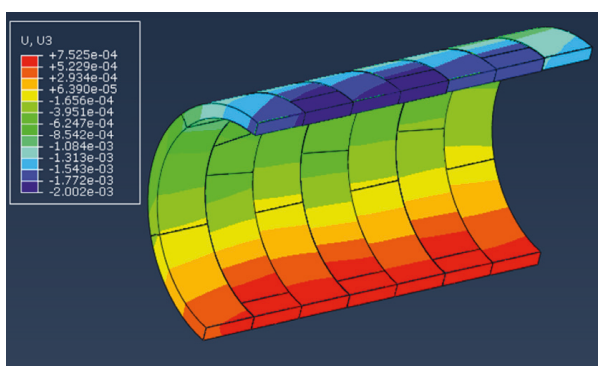

(a)

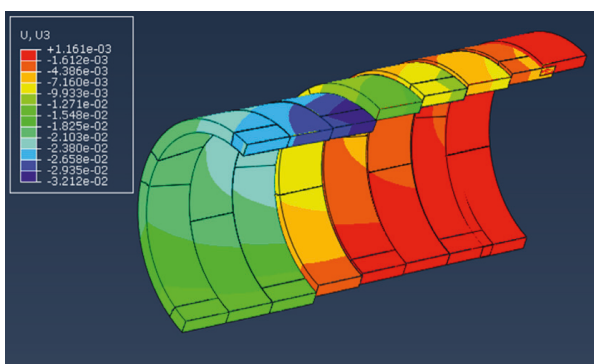

(b)

Figure 10: The segment deformation under different water drains. (a) No draining at the excavation face. (b) Fully drained at the excavation face.

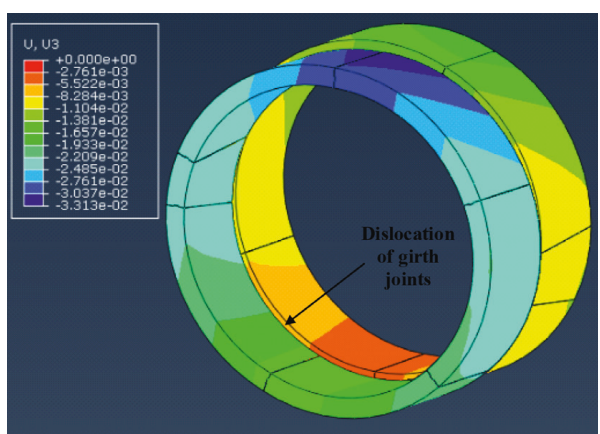

(a)

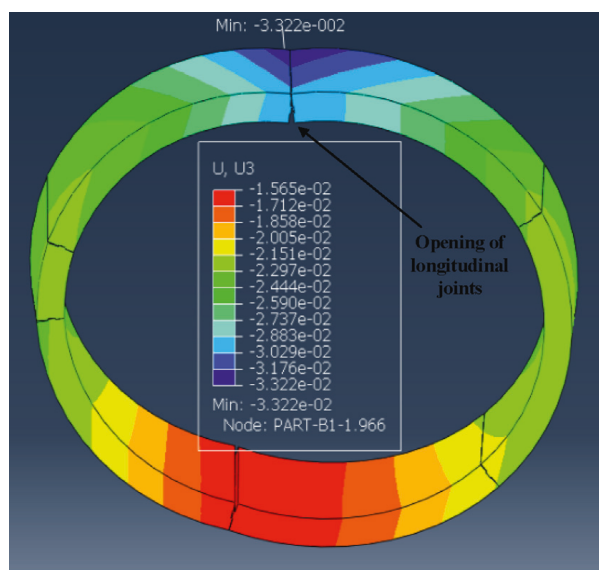

(c)

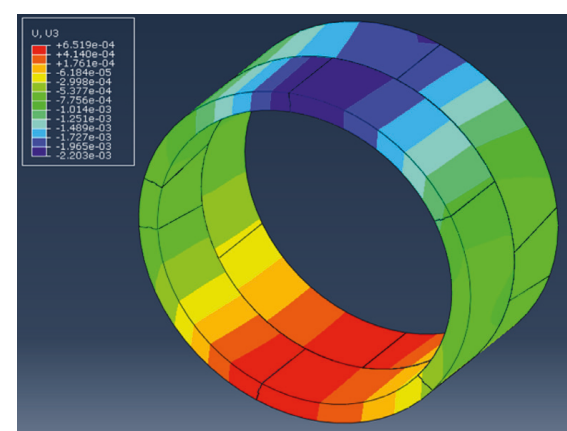

(b)

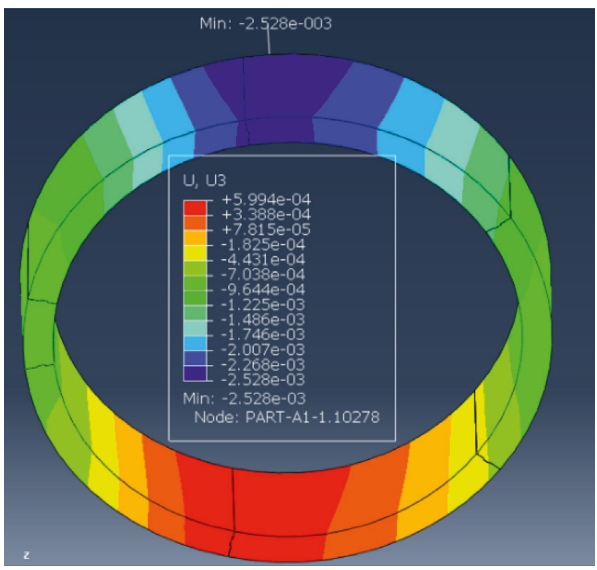

(d)

FIgURE 11: The effect of water inrush on segment deformation. Water head difference of (a) $18 \mathrm{~m}$ (20x) and (b) $0 \mathrm{~m}$ (20x).

longitudinal joint opening can be neglected. The size of joint opening exceeds the tolerance value for longitudinal joint specified in the metro design standard (3 mm), so water seepage may occur through longitudinal joints.

(3) When the water head difference over the excavation face reaches the limit value of $18 \mathrm{~m}$, the maximum dislocation of circumferential joint at tunnel vault reaches $15 \mathrm{~mm}$. When water inrush from the excavation face does not occur, the dislocation of circumferential joint is $0.3 \mathrm{~mm}$. As a result, remarkable dislocation of the circumferential joint at the tunnel vault occurs, nearly 50 times larger than that compared with the case without water inrush. When the dislocation exceeds the tolerance value of circumferential joint specified in the metro design standard $(15 \mathrm{~mm})$, the waterproof performance of the joint may be weakened.

3.3. Stress in Joint Concrete. During shield construction of the metro tunnel, the water gushing from the excavation face will inevitably change the state of stress in segment 
TABLE 3: Pore pressure and the corresponding water head difference at the excavation face.

\begin{tabular}{lcccccccc}
\hline Pore water pressure at excavation face $(\mathrm{kPa})$ & 0 & 20 & 40 & 70 & 100 & 130 & 160 & No pore \\
Reduction of water head difference at excavation face $(\mathrm{m})$ & 18.2 & 16.2 & 14.2 & 11.2 & 8.2 & 5.2 & 2.2 & 0 \\
\hline
\end{tabular}

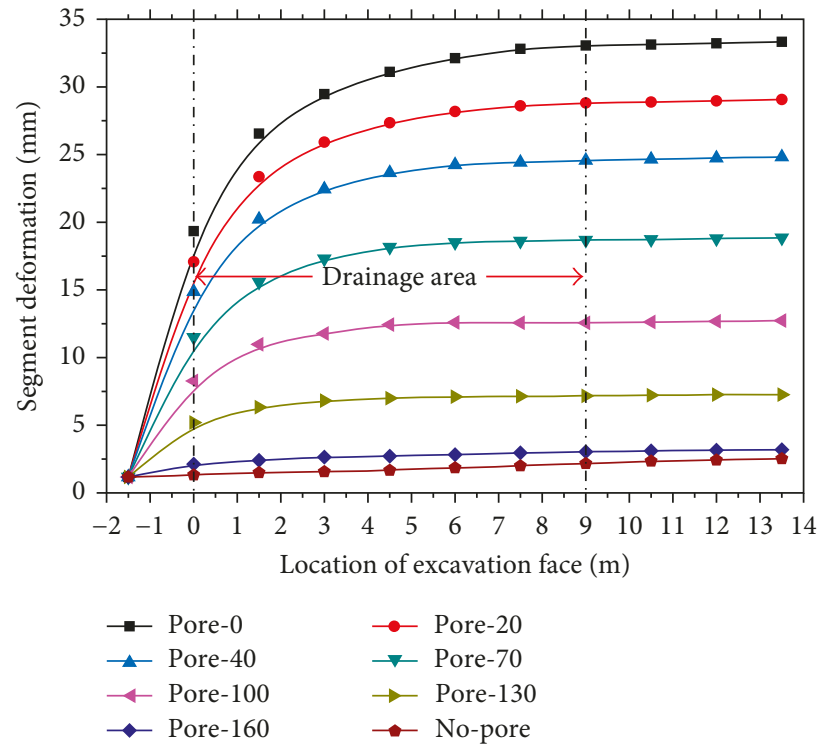

Figure 12: The maximum deformation of segment.

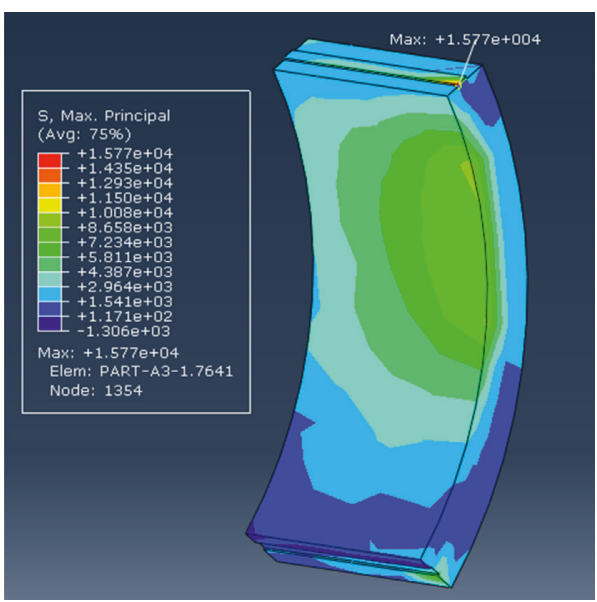

(a)

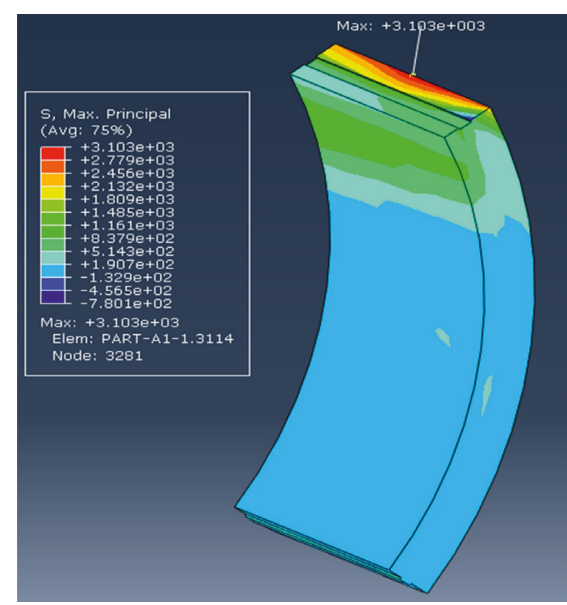

(b)

Figure 13: The effect of water head difference on the maximum tensile stress of segment. Water head difference of (a) $18 \mathrm{~m}$ and (b) $0 \mathrm{~m}$.

joints. In the critical Section D, nephograms of the tensile stress and compressive stress in segment joints under the condition of continuously changing amount of water gushing from the excavation face are shown in Figures 13 and 14 .

Continuous variation of water head difference over the excavation face results in stress concentration in segment joints. The maximum tensile stress in segment A1 is $3.1 \mathrm{MPa}$ before the occurrence of water inrush and becomes $15.77 \mathrm{MPa}$ after that, higher than the ultimate tensile strength of C50 concrete $(5 \mathrm{MPa})$. In such cases, the local concrete will suffer structural damage, and the maximum compressive stress will also change significantly. The maximum compressive stress in segment B1 is 10.23 $\mathrm{MPa}$ before water inrush occurs and becomes 35.41 MPa after that.

The concrete in the vicinity of the bolt in segment joints is subjected to greater tension and shear force, because the displacement of the segment joint is larger after the occurrence of water inrush. At the same time, the maximum 


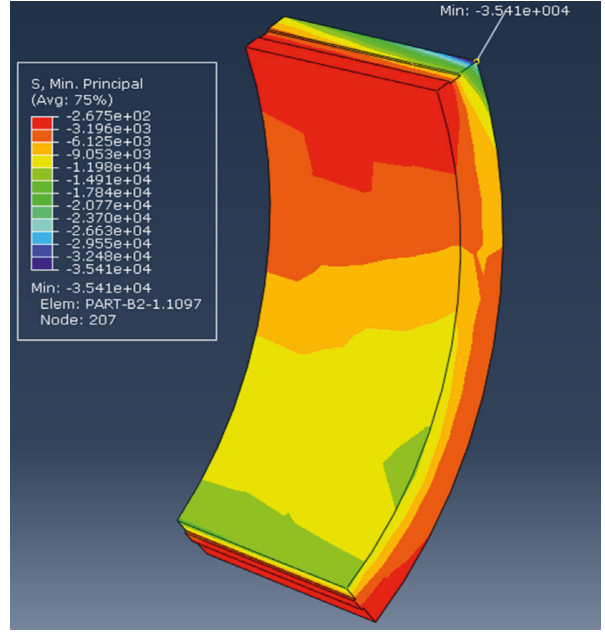

(a)

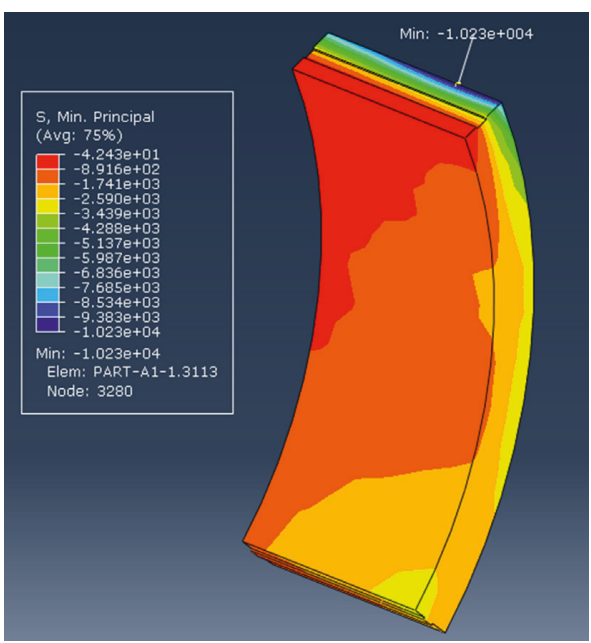

(b)

FIGURE 14: The effect of water head difference on the maximum compressive stress of segment. Water head difference of (a) $18 \mathrm{~m}$ and (b) $0 \mathrm{~m}$.

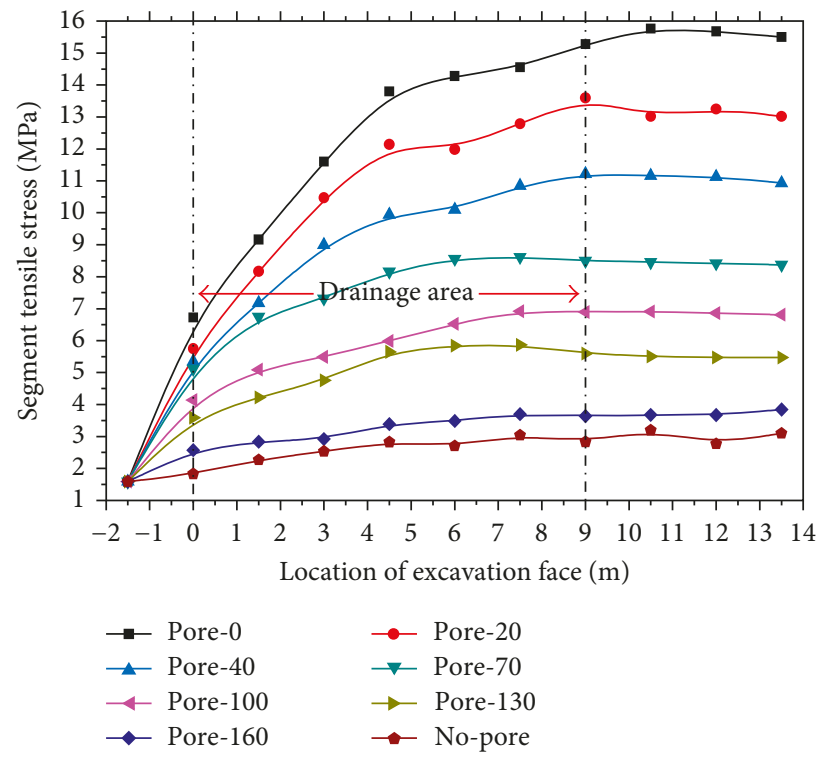

FIgURE 15: Maximum tensile stress at segment.

compressive stress in the concrete is $35.41 \mathrm{MPa}$, which occurs under the maximum tensile stress near the same bolt. Special attention should be paid to the abnormal state of stress in the concrete in the vicinity of the bolt in segment joints after the occurrence of water inrush from the excavation face.

The maximum tensile stress and maximum compressive stress in the concrete at segment joints change with the amount of water gushing from the excavation face, and the corresponding curves are shown in Figures 15 and 16.

(1) As shown in Figure 15, when the water head difference over the excavation face is greater than $5 \mathrm{~m}$, the stress in the concrete at the joints increases significantly and the maximum tensile stress in the segment will exceed the ultimate tensile strength. There is a risk of cracking at this time.
(2) For the local compressive stress in the concrete at the joints, the influence of the amount of water gushing from the excavation face on circumferential joints is greater than that on longitudinal joints. Considering the local tensile stress at the joints, the influence of the water head difference over the excavation face on circumferential joints is greater than that on longitudinal joints.

3.4. Internal Force of Coupling Bolt. The nephograms of the tension, shear, and moment of the bolt are shown in Figures 17-19. The internal force of the bolt varies with the degree of opening and dislocation of segment joints. When the amount of water gushing from the excavation face is large, the internal force is large in high-strength 


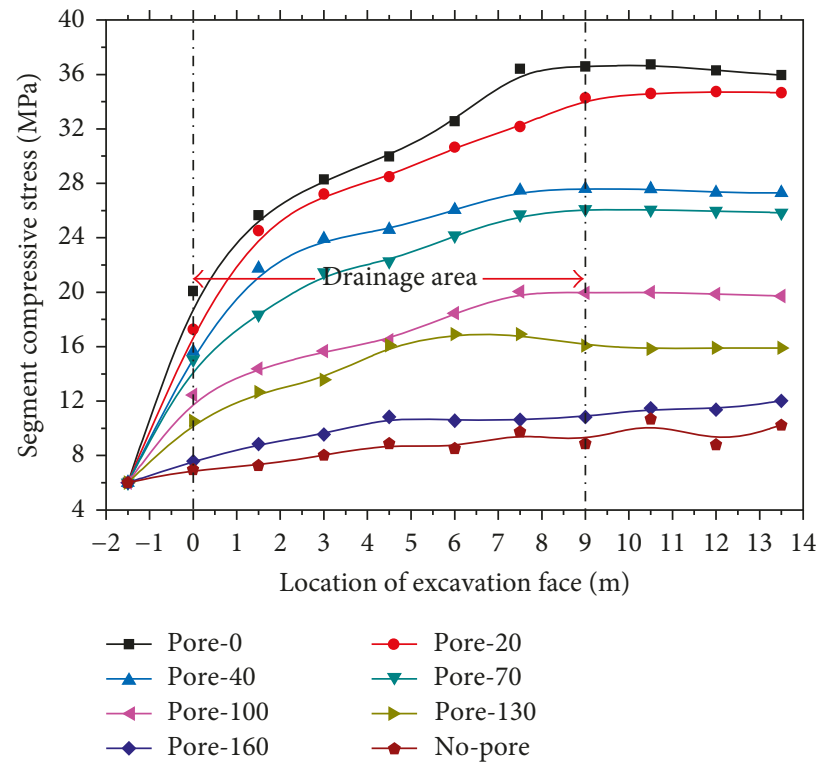

FIGURE 16: Maximum compressive stress at segment.

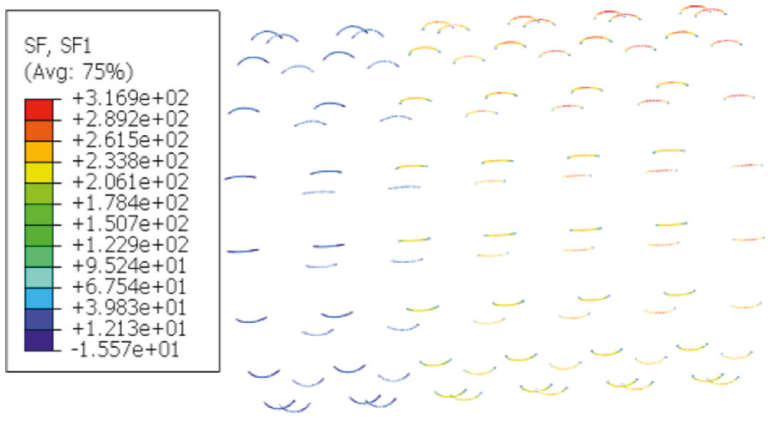

(a)

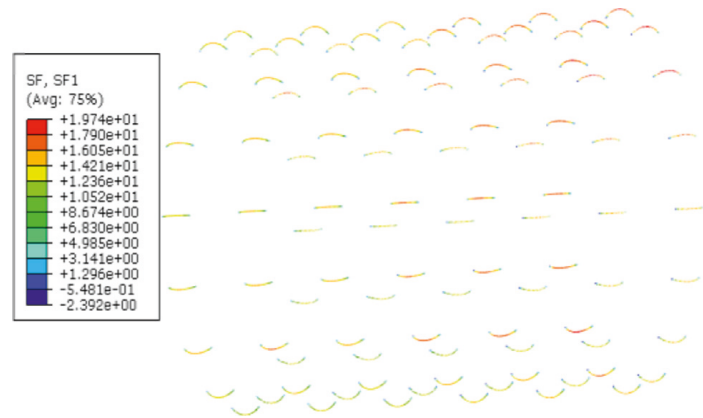

(b)

Figure 17: Tension diagram of bolt. Water head difference of (a) $18 \mathrm{~m}$ and (b) $0 \mathrm{~m}$.

bending bolt, and the tension- or shear-yielding damage and even fracture of bolts are easy to occur. For the common load-bearing carrier of bolts and segments, the destruction of one node will inevitably lead to progressive failure of the whole segment lining. This is extremely detrimental to the safety of the tunnel structure. Therefore, researchers need to find an approach to eliminate the influence of the water head over the excavation face on the internal force of the segment and control the water head difference over the excavation face to prevent the occurrence of hazards.

The variations of the maximum axial force, maximum shear force, and maximum bending moment with the progress of construction are shown in Figures 20-22. The strength and the distribution of axial force on the bolts of the segment joint change after the water inrush occurs from the excavation face. In the critical Section D, the axial force of the bolt increases sharply at the joint of the vault and arch of the tunnel. When the bolt is in a state with large deformation, its maximum tensile force reaches $316.9 \mathrm{kN}$, which is 16 times higher than that without drainage, and the maximum shear force is $561.2 \mathrm{kN}$, which is 14 times that before excavation. The maximum bending moment of bolt is $14.18 \mathrm{kN} * \mathrm{~m}$, nearly 13 times higher than that before drainage.

\section{Criterion of Emergency Control of Water Inrush from the Excavation Face in Shield Tunneling}

It is very difficult to monitor and measure the deformation and internal force of the segments and bolts in the vicinity of joints on the site of the metro tunnel. However, it is easier to monitor the amount of water gushing from the excavation face when it occurs. As shown in Figures 23-25, the influence of different seepage velocities in the drainage area on the whole construction process is analyzed, and the following data are sorted out: the maximum deformation of the segment at the segment joint during the entire course of drainage in the tunnel, the maximum tensile stress in the segment, the maximum compressive stress in the segment, the maximum tensile stress in the bolt, the maximum shear stress in the bolt, and the trend of variation of the maximum bending moment with per unit 


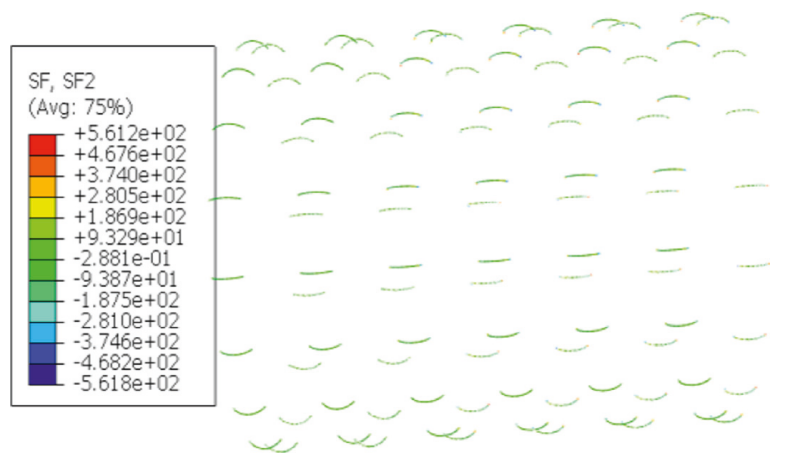

(a)

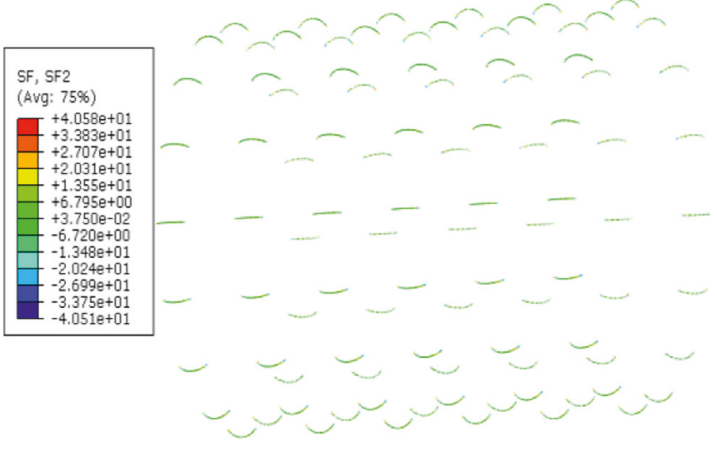

(b)

FIgURE 18: Shear diagram of bolt. Water head difference of (a) $18 \mathrm{~m}$ and (b) $0 \mathrm{~m}$.

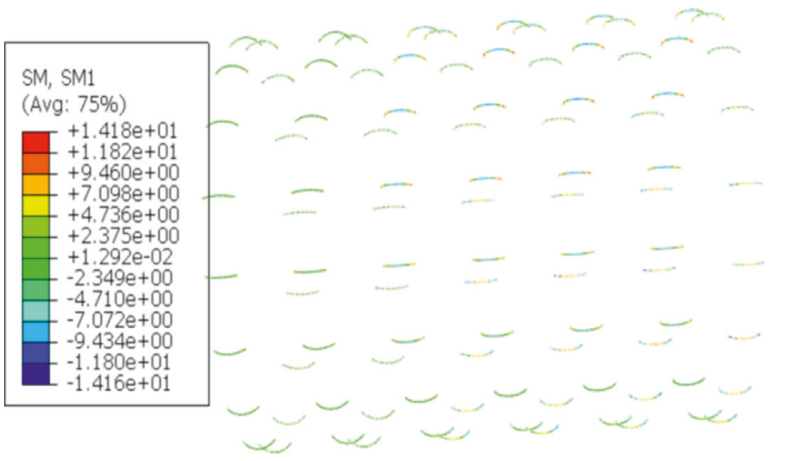

(a)

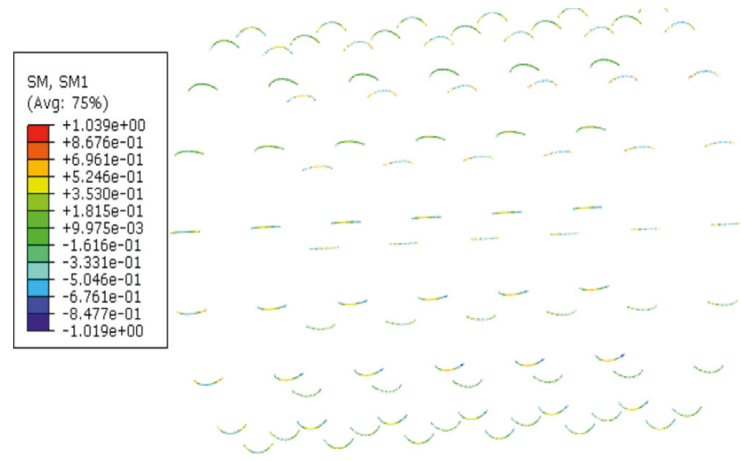

(b)

FIgURe 19: Moment diagram of bolt. Water head difference of (a) $18 \mathrm{~m}$ and (b) $0 \mathrm{~m}$.

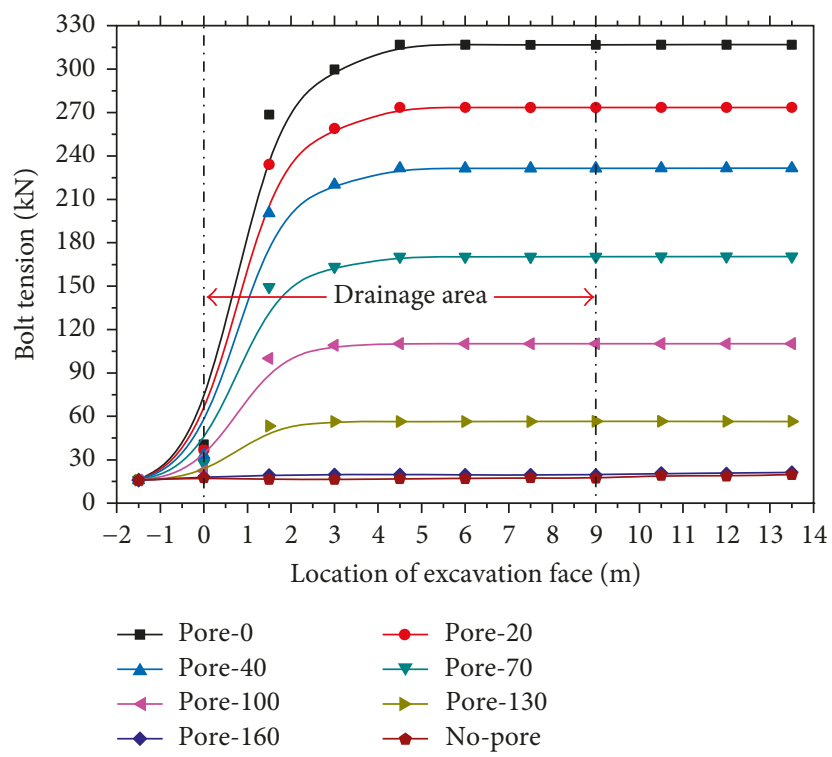

Figure 20: The maximum tension force of bolt.

water inrush at one step (mainly controlled by the water head difference $\Delta h$ ). As can be seen from the diagram, when the water gushing from the excavation face increases, the internal force and deformation in both the segment and bolt show a trend of nonlinear increase. For a C50-reinforced concrete segment, when the stress in the segment exceeds the tensile 


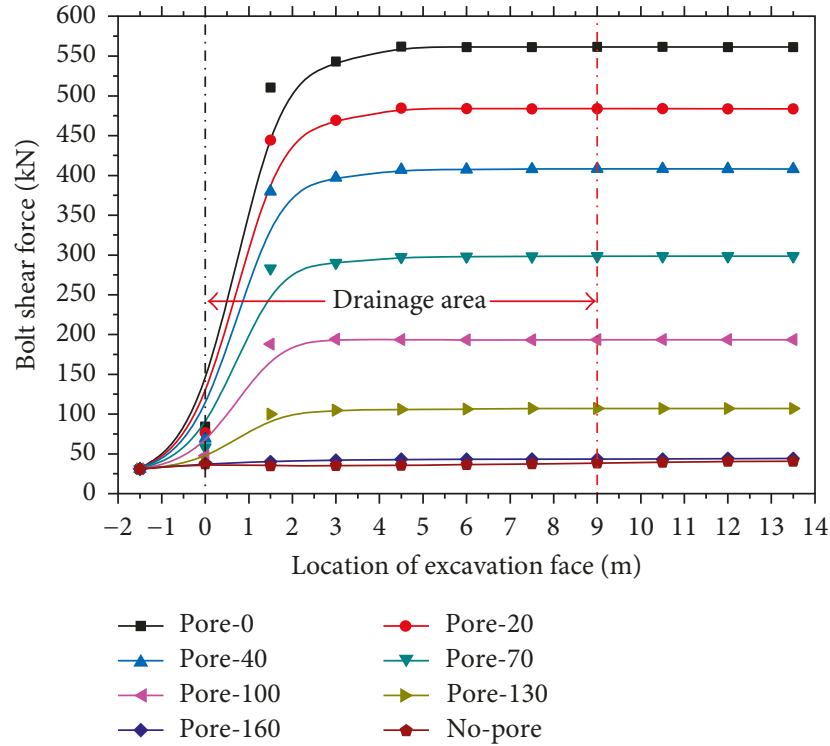

FIGURE 21: The maximum shear force of bolt.

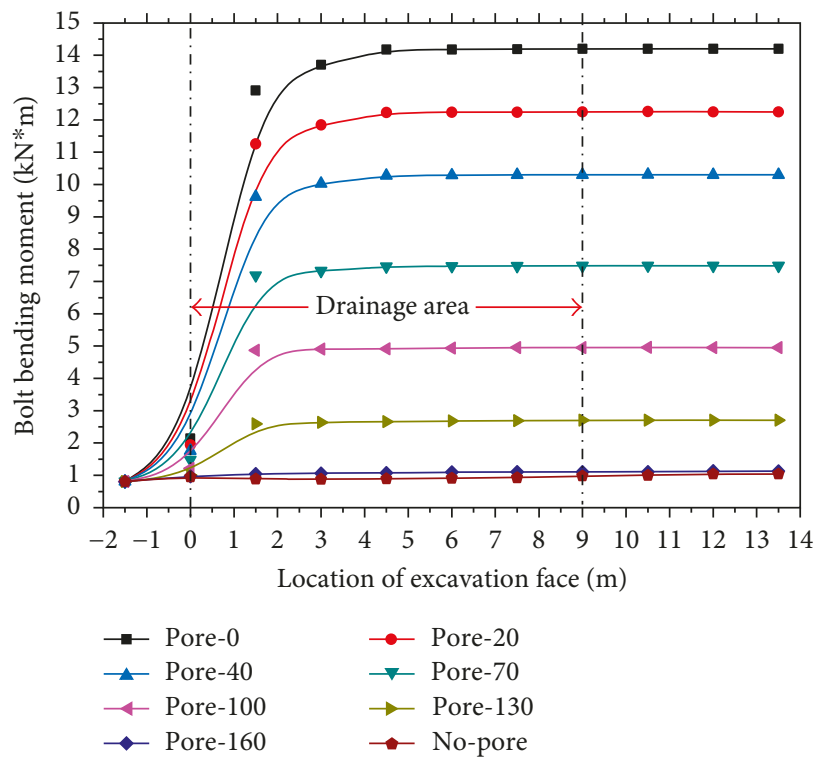

Figure 22: The maximum moment of bolt.

strength, the segment joint may crack, causing more serious water inrush. For a high-strength M30 bolt, excessive stress will lead to the yielding failure and threaten the safety of engineering structure. Therefore, in order to reduce the risk of segment fracture in case of water inrush from the excavation face, it is necessary to make emergency plans to control the water head difference over the excavation face. This result may provide reference for the engineering practice.

4.1. Relationship between Segment Deformation and Water Head Difference over the Excavation Face. During water inrush from the excavation face, the influence of

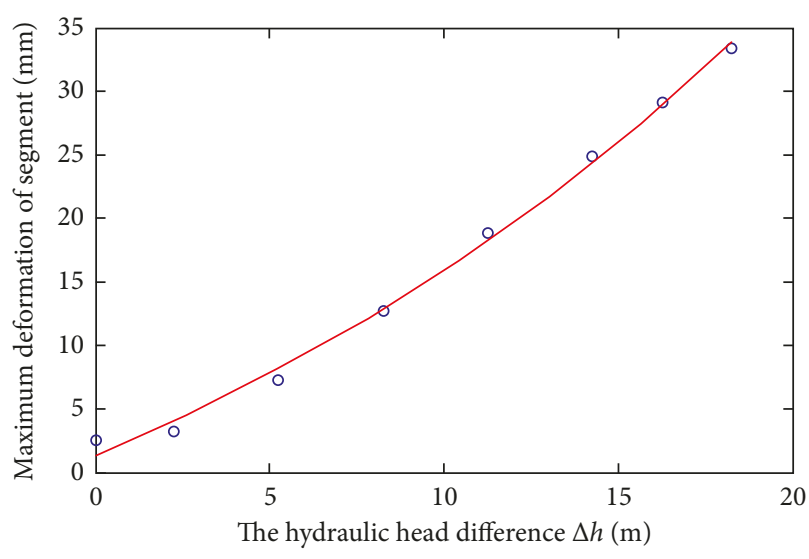

FIGURE 23: The relationship between the maximum deformation of the segment and the water head difference.

water head difference $\Delta h$ on the circumferential joint is greater than that on the longitudinal joint, and the amount of dislocation caused by the deformation of the segment connecting to a joint is mainly reflected in the circumferential joint. The relationship between the maximum deformation of the segment connecting to circumferential joint and the water head difference over the excavation face is shown in Figure 23. The relationship between the deformation of the maximum segment joint $\mu$ and the water head difference $\Delta h$ can be expressed by a function:

$$
u=-2.4482 \times 10^{1}+2.5838 \times 10^{1} \cdot e^{\Delta h / 2.2422 \times 10^{1}} .
$$

In order to ensure the waterproof performance of segment joint, the design specification of the joint deformation of the metro tunnel requires that the dislocation of circumferential joint should not be more than $15 \mathrm{~mm}$. According to the calculation above, the corresponding water head difference over tunnel lining should be less than $9.5 \mathrm{~m}$. Therefore, measures should be taken to ensure that the water head difference shall not be greater than $9.5 \mathrm{~m}$ in case that the amount of water gushing from the excavation face continuously changed during shield construction. It helps to control the amount of circumferential joint dislocation caused by the deformation of the segments connecting to the joint and to ensure the waterproof performance of tunnel segment joints.

4.2. Relationship between Segment Internal Force and Water Head Difference over the Excavation Face. The relationship between the tensile stress and compressive stress in the concrete constituting segment joints and the water head difference over the excavation face is shown in Figure 24, where $\sigma_{t}$ represents the maximum tensile stress in the concrete and $\sigma_{p}$ represents the maximum compressive stress in the concrete. The relationship between the maximum stress in the concrete and the water head difference index can be expressed by the following functions: 


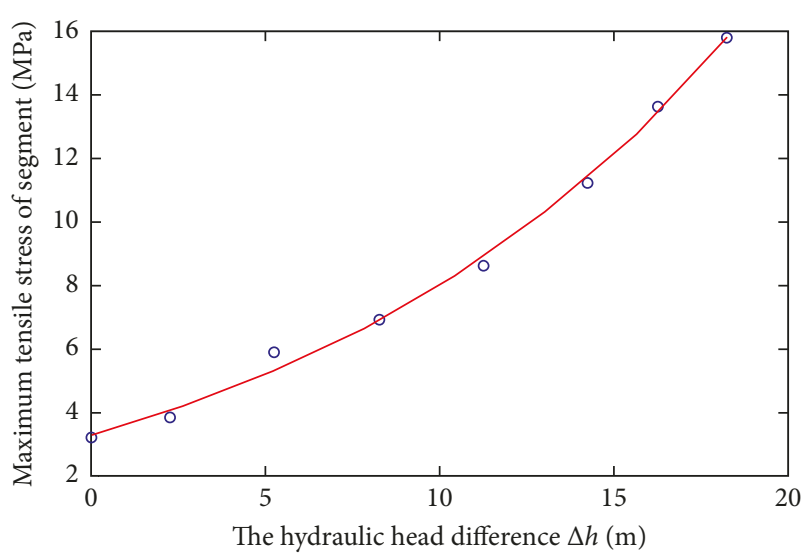

(a)

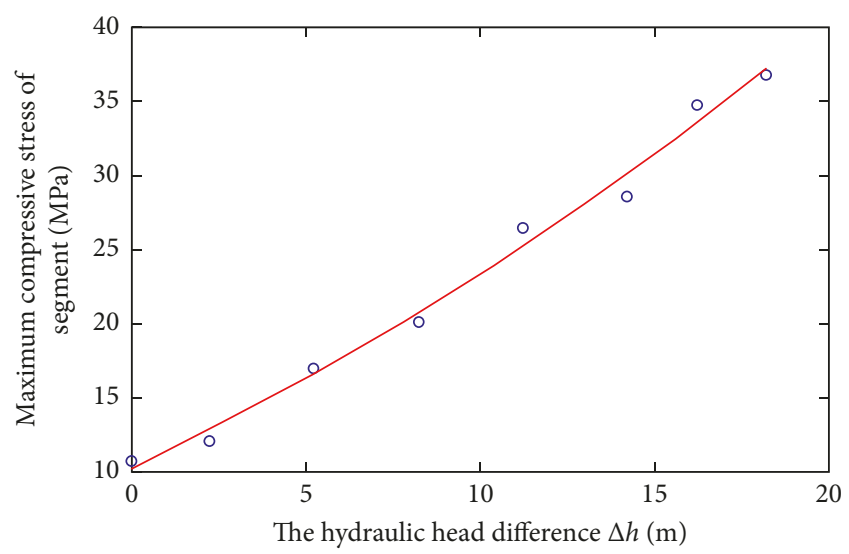

(b)

Figure 24: The relationship between the tensile and compressive stress in the concrete constituting segment joints and the water head difference over the excavation face. (a) The maximum tensile stress. (b) The maximum compressive stress.

$$
\begin{aligned}
& \sigma_{t}=-0.7394+4.0352 \cdot e^{\Delta h / 1.2958 \times 10^{1}}, \\
& \sigma_{p}=-2.9712 \times 10^{1}+3.9880 \times 10^{1} \cdot e^{\Delta h / 3.5329 \times 10^{1}} .
\end{aligned}
$$

The uniaxial compressive strength of the C50 concrete for subway segment is $50 \mathrm{MPa}$, and the corresponding water head difference over the excavation face is less than $24.5 \mathrm{~m}$. These values indicate that the concrete in the vicinity of the segment joint will not be crushed. The splitting tensile strength test [22] is conducted for the C50 segment concrete used in the Wuhan no. 7 subway line, and the obtained ultimate tensile strength is $5 \mathrm{MPa}$, and the corresponding water head difference over the excavation face is less than $4.6 \mathrm{~m}$. These values indicate that the concrete in the vicinity of the segment joint will not be damaged by excessive tension. Hence, in order to ensure the safety of segment joints, the water head difference over the excavation face should be less than $4.6 \mathrm{~m}$.

4.3. Relationship between the Internal Force of Bolts and the Water Head Difference over the Excavation Face. When the

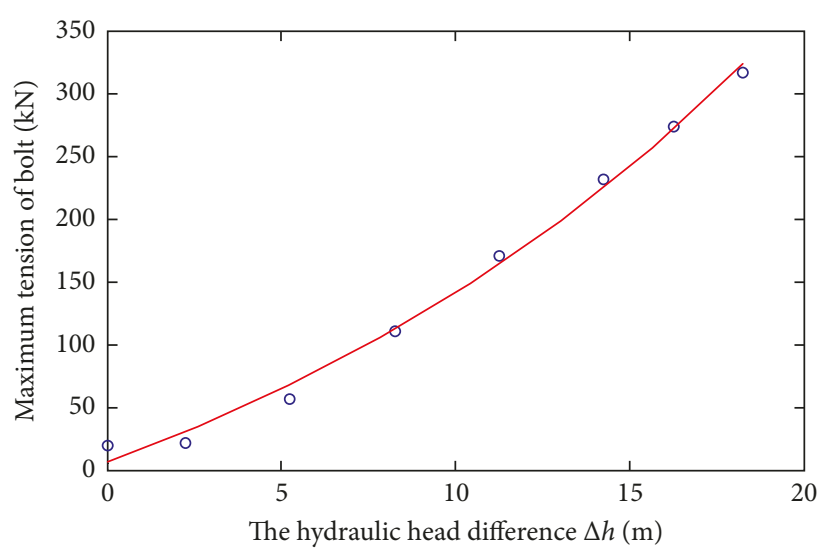

(a)

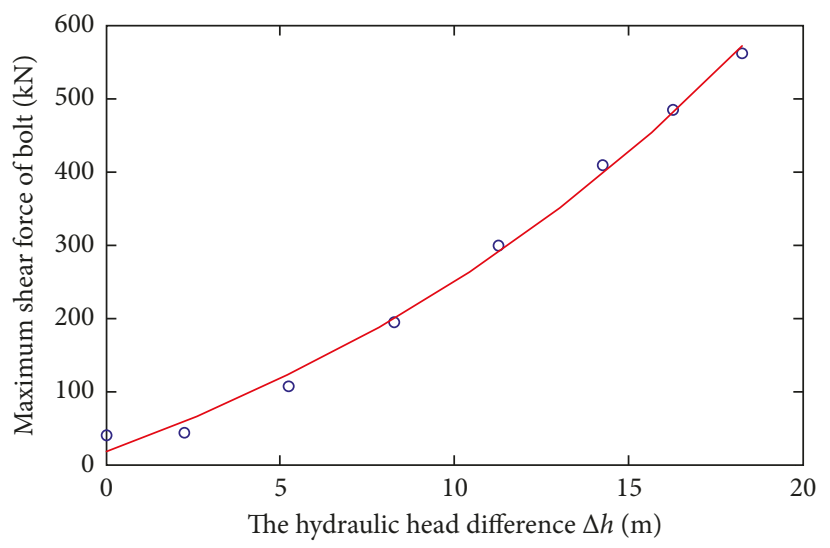

(b)

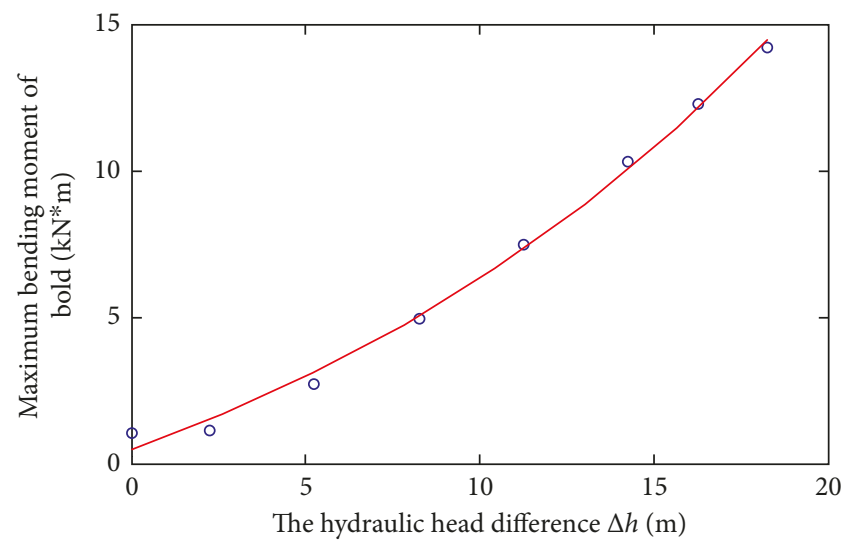

(c)

Figure 25: The relationship between the internal force of bolts and the water head difference over the excavation face. (a) The maximum axial force. (b) The maximum shear force. (c) The maximum bending moment.

amount of water gushing from the excavation face keeps varying in the process of shield construction, the relationship between the internal force of bolts connecting adjacent segments and the water head difference over the excavation face is also shown in Figure 25, where $N$ represents the maximum axial force acting on the bolt, $Q$ represents the maximum shear force, and $M$ represents the maximum bending moment. The relationship between 
the maximum internal force and the total deformation index of the connecting bolts can be expressed by the following functions:

$$
\begin{aligned}
& N=-1.8249 \times 10^{2}+1.8872 \times 10^{2} \cdot e^{\Delta h / 1.8532 \times 10^{1}}, \\
& Q=-2.7460 \times 10^{2}+2.9337 \times 10^{2} \cdot e^{\Delta h / 1.7224 \times 10^{1}}, \\
& M=-6.8056+7.2993 \cdot e^{\Delta h / 1.7069 \times 10^{1}} .
\end{aligned}
$$

The minimum tensile strength of the 8.8 grade bolt reaches $830 \mathrm{MPa}$, and the shear strength reaches $320 \mathrm{MPa}$. Therefore, the axial force and shear force of the M30 bolt are 466 and $215 \mathrm{kN}$, respectively, and the corresponding water head difference is $22.9 \mathrm{~m}$ and $8.8 \mathrm{~m}$, respectively. Therefore, in order to avoid the yielding of bolts connecting adjacent tunnel segments, the water head difference over the excavation face should be less than $8.8 \mathrm{~m}$.

In a word, in order to guarantee the long-term safety of segments and joints of a metro shield tunnel, the water head difference over the excavation face should not be greater than $4.6 \mathrm{~m}$ under the condition of water inrush from the excavation face. The water head difference can be adjusted by controlling the discharge of water on site.

\section{Conclusions}

When water inrush occurs in the process of shield construction of the metro tunnel, the water head difference over the excavation face varies. With the aim of studying the influences of continuous water inrush from the excavation face on the mechanical properties and deformation of segment joints (including the deformation and internal force of the segments and bolts in the vicinity of joints), a multiscale hybrid model of the excavation face in a shield tunnel is constructed based on the three-dimensional nonlinear contact theory and applied to simulate a section of XWS. The results of this study may provide reference for the engineering practice of shield tunneling. The following conclusions are drawn:

(1) The vertical convergence of the shield tunnel mainly reflects the overall deformation of the existing tunnel during the continuous change of water inflow at the excavation face. Dislocation of circumferential joints and opening of longitudinal joints are observed, and after excavation, the extent of both segment joint opening and dislocation is 16.5 times higher than that when the excavation face has no drainage. This situation directly results in a significant reduction in the effectiveness of the waterproof function of joints.

(2) The stress at the segment joints and connecting bolts changes sharply because of the constant change of water inrush at the excavation face. The local tensile stress of the segment exceeds the tensile strength limit of the C50 concrete; the axial force of the bolt is greater at the crown and the waist; in the critical position $\mathrm{D}$, the shear force of the bolt on the circumferential joint increases significantly, and the maximum shear force of the bolt reaches $561.2 \mathrm{kN}$.
(3) The emergency control standard should be established based on the water head difference $\Delta h$ of the excavation face during the tunnel construction. When the water head difference is over $4.6 \mathrm{~m}$ with continuously changing rate of water inrush from the excavation face, the limits of deformation and stress of segment joints are considered to have reached, and the risks of segment dislocation and extrusion cracking are increased. The research team will conduct further centrifuge simulation experiments to enhance the reliability of the calculation results.

\section{Conflicts of Interest}

The authors declare that they have no conflicts of interest.

\section{Acknowledgments}

The project was financed by the National key R\&D Program of China (Grant no. 2017YF0805500) and the National Natural Science Foundation of China (Grant no. 71390524). The authors thank the workers, foremen, and safety coordinators of the main contractors for their participation. The authors also wish to thank the engineer Peilun Tu for the assistance in gathering field data.

\section{References}

[1] Y. Liu, "Tesla CEO imagine underground highway system to ease traffic congestion," 2017, http://nb.ifeng.com/a/20170503/ 5627700_0.shtml.

[2] W. Liu, X. Wu, L. Zhang, J. Zheng, and J. Teng, "Global sensitivity analysis of tunnel-induced building movements by a precise metamodel," Journal of Computing in Civil Engineering, vol. 31, no. 5, p. 04017037, 2017.

[3] W. F. Lee and K. Ishihara, "Forensic diagnosis of a shield tunnel failure," Engineering Structures, vol. 32, no. 7, pp. 1830-1837, 2010.

[4] E. H. Davis, M. J. Gunn, R. J. Mair, and H. N. Seneviratine, "The stability of shallow tunnels and underground openings in cohesive material," Geotechnique, vol. 30, no. 4, pp. 397416, 1980.

[5] T. Krause, Schildvortrieb mit flüssigkeits-und erdgestützter ortsbrust, Ph.D. thesis, Technical University Carolo-Wilhelmina, Braunschweig, Germany, 1987.

[6] E. Leca and L. Dormieux, "Upper and lower bound solutions for the stability of shallow circular tunnels in frictional material," Geotechnique, vol. 40, no. 8, pp. 581-606, 1990.

[7] R. I. Borja, "A finite element model for strain localization analysis of strongly discontinuous fields based on standard Galerkin approximation," Computer Methods in Applied Mechanics and Engineering, vol. 190, no. 11-12, pp. 1529-1549, 2000.

[8] P. A. Vermeer, N. M. Ruse, and T. Marcher, "Tunnel heading stability in drained ground," Felsbau, vol. 20, no. 6, pp. 8-18, 2002.

[9] H. Schuller and H. F. Schweiger, "Application of a multilaminate model to simulation of shear band formation in NATM-tunnelling," Computers and Geotechnics, vol. 29, no. 7, pp. 501-524, 2002.

[10] C. E. Augarde, A. V. Lyamin, and S. W. Sloan, "Stability of an undrained plane strain heading revisited," Computers and Geotechics, vol. 30, no. 5, pp. 419-430, 2003. 
[11] I.-M. Lee, S.-W. Nam, and J.-H. Ahn, "Effect of seepage forces on tunnel face stability," Canadian Geotechnical Journal, vol. 20, no. 19, pp. 273-281, 2004.

[12] G. Mollon, D. Dias, and A.-H. Soubra, "Face stability analysis of circular tunnels driven by a pressurized shield," Journal of Geotechnical and Geoenvironmental Engineering, vol. 136, no. 1, pp. 215-229, 2010.

[13] P. Perazzelli, T. Leone, and G. Anagnostou, "Tunnel face stability under seepage flow conditions," Tunnelling and Underground Space Technology, vol. 43, pp. 459-469, 2014.

[14] S. Teachavorasinskun and T. Chub-uppakarn, "Influence of segmental joints on tunnel lining," Tunnelling and Underground Space Technology, vol. 25, no. 4, pp. 490-494, 2010.

[15] Y. D. Jian and W. Xin, "Study on flexural rigidity of segment joints in metro shield tunnel," Applied Mechanics and Materials, vol. 20, no. 170-173, pp. 1716-1721, 2012.

[16] N.-A. Do, D. Dias, P. Oreste, and I. Djeran-Maigre, “Threedimensional numerical simulation of a mechanized twin tunnels in soft ground," Tunnelling and Underground Space Technology, vol. 42, pp. 40-51, 2014.

[17] M. Nikkhah, S. S. Mousavi, S. Zare, and O. Khademhosseini, "Evaluation of structural analysis of tunnel segmental lining using beam-spring method and force-method (case study: Chamshir water conveyance tunnel)," Journal of Mining \& Environment, vol. 8, no. 1, pp. 111-130, 2017.

[18] Z. Wang, L. Wang, L. Li, and J. Wang, "Failure mechanism of tunnel lining joints and bolts with uneven longitudinal ground settlement," Tunnelling and Underground Space Technology, vol. 40, pp. 300-308, 2014.

[19] S. Chenghua, C. Chengyong, L. Mingfeng, P. Limin, and A. Huijun, "Effects of lateral unloading on the mechanical and deformation performance of shield tunnel segment joints," Tunnelling and Underground Space Technology, vol. 51, pp. 175-188, 2016.

[20] F. Colella, G. Rein, R. Carve, P. Reszka, and J. L. Torero, "Analysis of the ventilation systems in the Dartford tunnels using a multi-scale modelling approach," Tunnelling and Underground Space Technology, vol. 25, no. 4, pp. 423-432, 2010.

[21] G. Nilakantan, M. Keefe, T. A. Bogetti, and J. W. Gillespie, "Multiscale modeling of the impact of textile fabrics based on hybrid element analysis," International Journal of Impact Engineering, vol. 37, no. 10, pp. 1056-1071, 2010.

[22] G. Pinwu, G. Jianhua, Z. Juanrong, and Y. Xiaolong, "Study on mix proportion design and properties of high-performance concrete for subway tunnel segment," Concrete, vol. 4, pp. 130-132, 2013. 


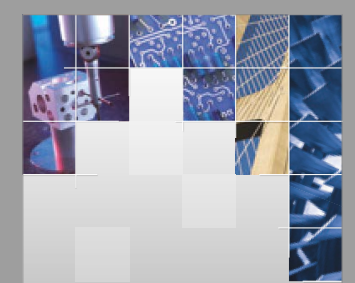

\section{Enfincering}
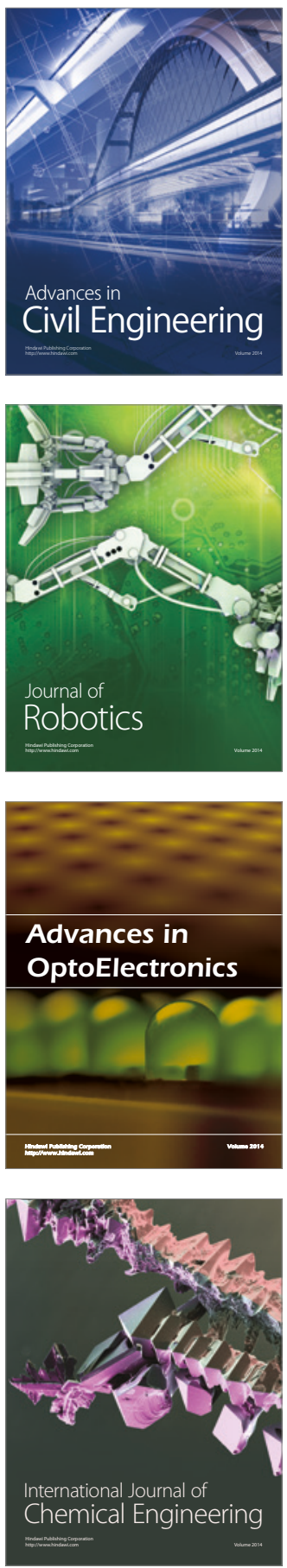

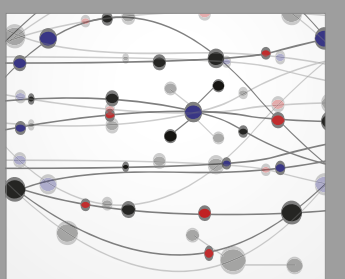

The Scientific World Journal

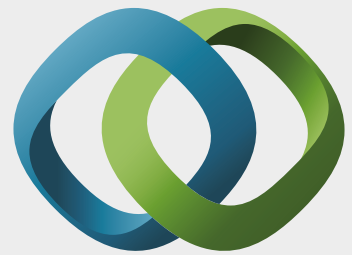

\section{Hindawi}

Submit your manuscripts at

https://www.hindawi.com
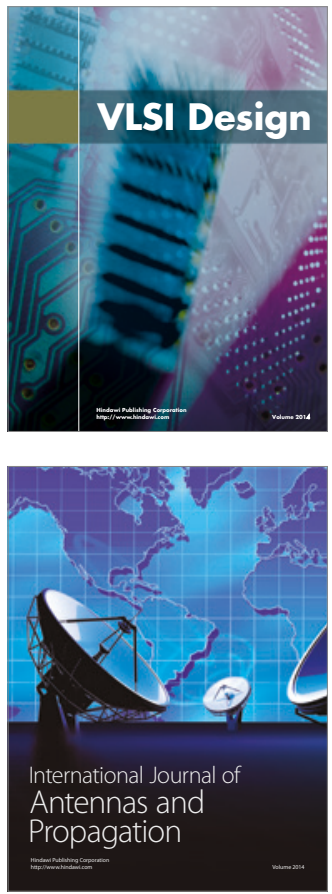

\section{Rotating}

Machinery
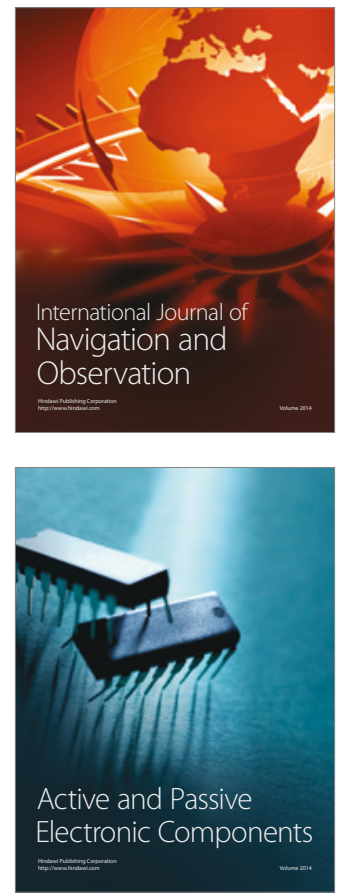
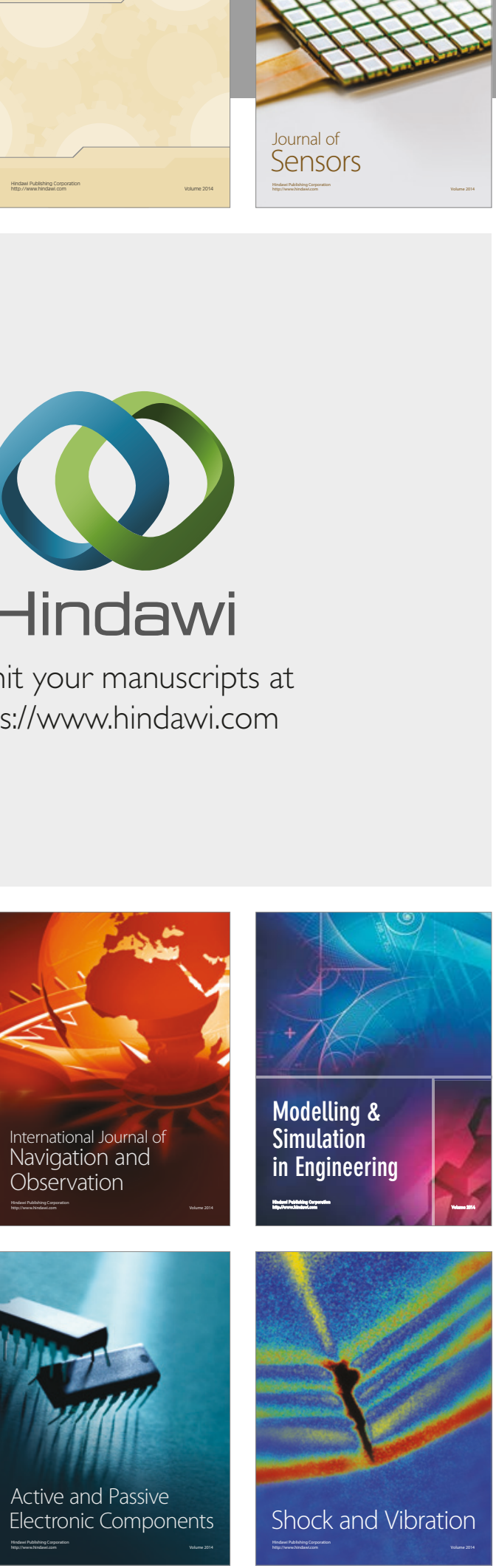
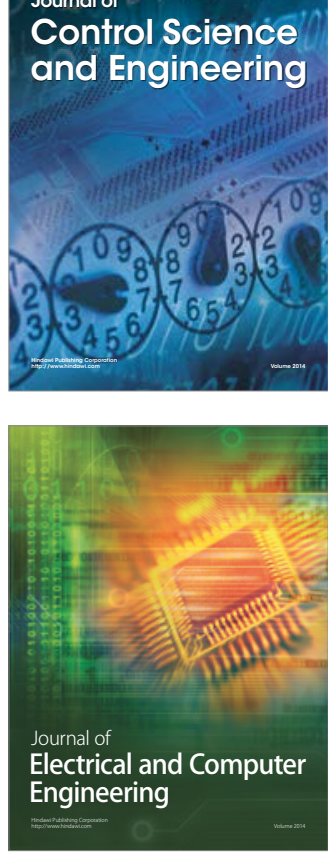

Distributed

Journal of

Control Science

and Engineering
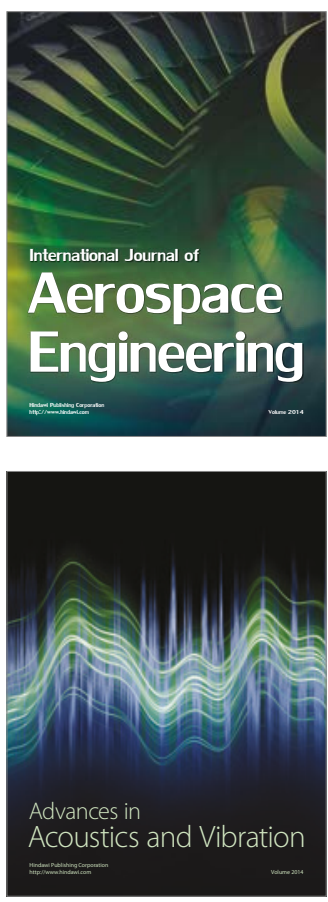

Sensor Networks 